Int. J. Dev. Biol. 58: 895-908 (2014)

doi: $10.1387 / \mathrm{ijdb} .140255 \mathrm{jg}$

\title{
Digit evolution in gymnophthalmid lizards
}

\author{
JULIANA G. ROSCITO*,1, PEDRO M.S. NUNES² and MIGUEL T. RODRIGUES ${ }^{1}$ \\ ${ }^{1}$ Departamento de Zoologia, Instituto de Biociências, Universidade de São Paulo-SP and \\ ${ }^{2}$ Departamento de Zoologia, Centro de Ciências Biológicas, Universidade Federal de Pernambuco, Brazil
}

\begin{abstract}
The tetrapod limb is a highly diverse structure, and reduction or loss of this structure accounts for many of the limb phenotypes observed within species. Squamate reptiles are one of the many tetrapod lineages in which the limbs have been greatly modified from the pentadactyl generalized pattern, including different degrees of reduction in the number of limb elements to complete limblessness. Even though limb reduction is widespread, the evolutionary and developmental mechanisms involved in the formation of reduced limb morphologies remains unclear. In this study, we present an overview of limb morphology within the microteiid lizard group Gymnophthalmidae, focusing on digit arrangement. We show that there are two major groups of limbreduced gymnophthalmids. The first group is formed by lizard-like (and frequently pentadactyl) species, in which minor reductions (such as the loss of 1-2 phalanges mainly in digits I and V) are the rule; these morphologies generally correspond to those seen in other squamates. The second group is formed by species showing more drastic losses, which can include the absence of an externally distinct limb in adults. We also present the expression patterns of Sonic Hedgehog (Shh) in the greatly reduced fore and hindlimb of a serpentiform gymnophthalmid. Our discussion focuses on identifying shared patterns of limb reduction among tetrapods, and explaining these patterns and the morphological variation within the gymnophthalmids based on current knowledge of the molecular signaling pathways that coordinate limb development.
\end{abstract}

KEY WORDS: limb reduction, reptiles, morphological evolution, limb development

\section{Introduction}

The tetrapod limb has been the subject of extensive investigation in evolutionary and developmental biology for over a century. Since the $19^{\text {th }}$ century, the evolutionary origin and diversification of the limbs have been greatly debated, and several hypothesis and mechanisms have been proposed to explain how such diversity arose.

Studies in several research areas, including evolutionary biology, paleontology, ecology, anatomy, physiology, functional morphology and, to a lesser degree, developmental biology, have focused on understanding the evolution and diversification of the reptile limb (Gans, 1975; Lande, 1978; Withers, 1981; Greer, 1991; Benesch and Whithers, 2002; Caldwell, 2002; Shapiro, 2002; Shapiro et al., 2003; Whiting et al., 2003; Crumly and Sanchez-Villagra, 2004; Kearney and Stuart, 2004; Kohlsdorf and Wagner, 2006; Wiens et al., 2006, Brandley et al., 2008; Kohlsdorf et al., 2008; Russel and Bauer, 2008; Skinner et al., 2008; Bergmann and Irschick, 2009;
Jerez and Tarazona, 2009; Young et al., 2009; Leal et al., 2010; Hugi et al., 2012; Camacho et al., 2014, etc).

One frequent modification of limb morphology among squamate reptiles (lizards, snakes, and amphisbaenians) is limb reduction. From minor losses of phalanges, to the complete loss of the limb, there is a wide spectrum of intermediate morphologies that can occur even among species that belong to the same genus (Choquenot and Greer, 1989; Skinner et al., 2008). Changes like those are extremely frequent, having occurred multiple times independently in almost all major squamate groups (Greer, 1991; Wiens et al., 2006; Skinner et al., 2008). The scincids and anguids top the rank of limb-reduced lineages, but reduction is also seen in the pygopodids, gekkonids, cordylids, gerrhosaurids, dibamids, gymnophthalmids, amphisbaenians, and, obviously, in the snakes. Even though the

Abbreviations used in this paper: AER, apical ectodermal ridge; $\mathrm{Bmp}$, bone morphogenetic protein; d, digit; Fgf, fibroblast growth factor; mc, metacarpal; Shh, sonic hedgehog; Wnt, wingless homologue gene.

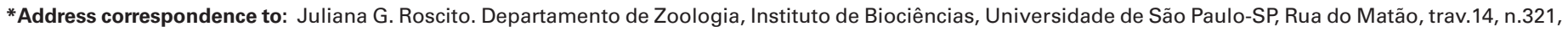
Cidade Universitária, São Paulo-SP, Brasil. CEP: 05508-090. Tel: +55-11-3091-7570. E-mail: juroscito@gmail.com
}

Supplementary Material (one table) for this paper is available at: http://dx.doi.org/10.1387/ijdb.140255jg

Accepted: 19 December 2014

ISSN: Online 1696-3547, Print 0214-6282 
identification of evolutionary patterns of limb evolution is crucial, the fundamental question of how such diversity arises is better answered by studying the mechanisms involved in the formation of the limbs. Most of the studies comprise morphological analyses of limb development, and are important for laying the anatomical foundations for further functional investigations (for example, Howes and Swinnerton, 1901; Mathur and Goel, 1976; Rieppel, 1994; Shapiro, 2002; Fabrezi et al., 2007; Leal et al., 2010; Roscito and Rodrigues, 2012a,b), but few studies (Raynaud, 1990; Raynaud et al., 1998; Cohn and Tickle, 1999; Shapiro et al., 2003; Young et al., 2009) attempted to undercover the molecular mechanisms behind limb development in natural populations of squamate species.

In this paper we present an extensive survey of the limbs of several lizard species belonging to the South American Gymnophthalmidae group, with the aim of identifying patterns of limb reduction (Fig. 1). We also present a preliminary investigation of the molecular signaling involved in the formation of a reduced limb, and analyse the different types of reduction based on the current knowledge of the mechanisms controlling limb development in vertebrates.

\section{Results}

\section{Digit arrangement in gymnophthalmid lizards}

The phalangeal formula of both fore and hindlimb, as well as specific notes on the morphology of metacarpal/metatarsal and phalangeal elements, are presented in Table 1.

The typical squamate pentadactyl condition (Romer, 1956) is that of 5 digits in both fore and hindlimb, with a specific number of phalanges in each digit (Fig. 2):

Forelimb $=(5) 2 \cdot 3 \cdot 4 \cdot 5.3$

Hindlimb $=(5) 2 \cdot 3 \cdot 4 \cdot 5 \cdot 4$

Most gymnophthalmid species have limbs following the generalized pentadactyl arrangement, which is the case for all cercosaurinis and alopoglossinis, and a few other species from the Ecpleopodinae. Other species show a full pentadactyl arrangement but exhibit a reduction in size of one or both phalanges of digit I of the forelimb; the majority of species from the Iphisiini (Rodrigues et al., 2009) show a slight reduction in the size of the ungueal phalanx from dl, with Alexandresaurus, Colobosaura (Fig. 3D), and Stenolepis (Fig. $3 \mathrm{E})$ bearing no claw in this digit; in Iphisa, both phalanges seem reduced. Reduction is not clear in Acratosaura, more material is needed in order to confirm whether its limbs share the morphology of its relatives.

Tretioscincus is the other genus in which a clear reduction in size of phalanges in dl can be observed; the other gymnophthalmini
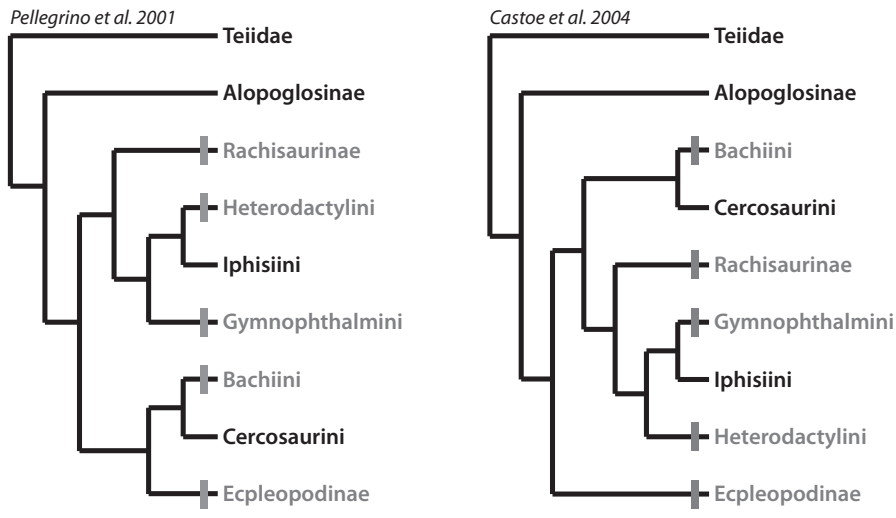

species have lost either one (Gymnophthalmus) or both phalanges from dl of the forelimb (Micrablepharus, Psilophthalmus, Procellosaurinus, Vanzosaura) (Fig. 4 A-D).

Complete loss of $\mathrm{dl}$ of the forelimb, as seen in the beforementioned gymnophthalmini species, occurs only in Rachisaurus brachylepis (Fig. 4 E,F). Colobodactylus' dl of the forelimb is clearly reduced; this is in disagreement with Kizirian and McDiarmid (1998) and Grizante (2009), who report only the presence of mcl. However, it is possible that there is intrapopulational variation for this character; the presence of a vestigial ossification distal to $\mathrm{mc} 1$ in C. taunay (MTR 746) and the apparent absence of such element in the second individual (MZUSP 94254) argue in favor of this variation (Fig. $3 \mathrm{~B}, \mathrm{C})$.

Interestingly, all those species in which both phalanges from dl of the forelimb are lost, the corresponding metacarpal $(\mathrm{mcl})$ is always present. Also worth of notice is that in all previously mentioned cases, the minor reductions, or loss of dl, are not accompanied by reductions/losses in the hindlimbs, which maintain the pentadactyl arrangement. The exception is Rachisaurus brachylepis, which has lost one phalanx from dl, and all phalanges from dV of the hindlimb; this condition is not seen in any of the other Gymnophthalmidae analysed.

Another "type" of reduction is seen in some species of the Ecpleopodinae: while most are pentadactylous, Anotosaura and Dryadosaura have lost the last phalanx of dIV of the forelimb. In addition, in Anotosaura collaris the last phalanx of dV of the hindlimb is absent (Fig. 3A; its sister species, A. vanzolinia, shows the full pentadactyl arrangement). The single individual of Colobosauroides cearensis analysed shows a left-right asymmetry in the number of phalanges in dIV of the forelimb.

Limb reduction reaches extreme cases in two gymnophthalmid lineages: the Gymnophthalmini, with Nothobachia and Calyptommatus (and possibly Scriptosaura; Rodrigues and dos Santos, 2008), and the Bachiini (Fig. 5).

Within the Gymnophthamini (Fig. 5 E-J), Nothobachia still retains both fore and hindlimbs, although they are very reduced (forelimb styliform and hindlimb with two digits) and presumably not functional for fast walking (Renous et al., 1998). Scriptosaura and Calyptommatus show even further reductions: both lack the forelimb, although retaining a vestigial internal humerus close to the pectoral girdle (Scriptosaura has, in addition, a vestige of the second limb segment; Roscito and Rodrigues, 2013); both species have a styliform hindlimb.

Bachia is a very interesting genus with respect to the diversity of limb morphologies. Limb reduction in Bachia species is more

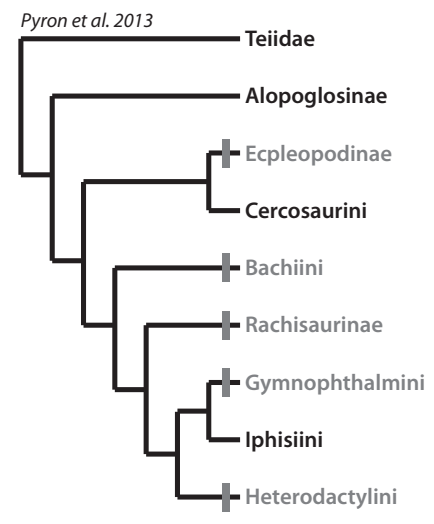

Fig. 1. Relationships within the Gymnopthalmidae. Adapted from the phylogenetic hypotheses of Pellegrino et al., (2001), Castoe et al., (2004), and Pyron et al., (2013). Lineages with limb-reduced species are marked in grey. 


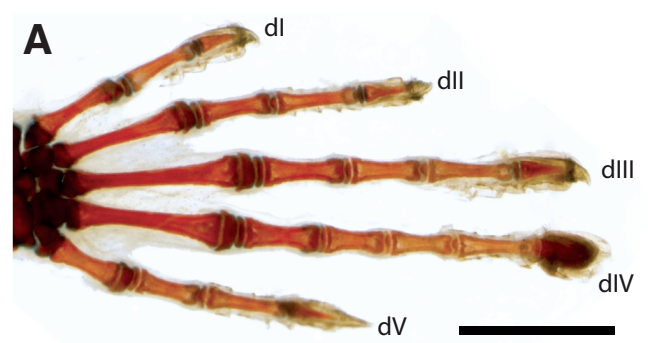

B

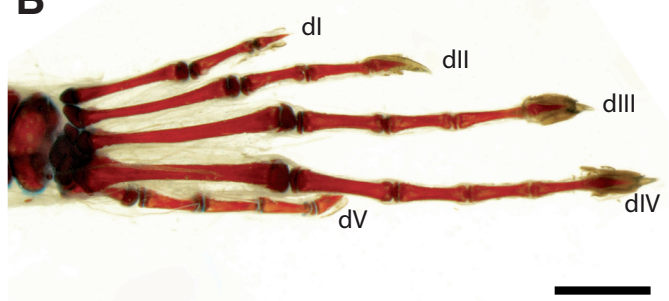

Fig. 2. Forelimb (A) and hindlimb (B) of Cercosaura schreibersi, showing the generalized phalangeal arrangement. Digit identity is indicated as $d l-d V$. Anterior to the top. Scale bar, $1 \mathrm{~mm}$. pronounced in the hindlimbs than in the forelimbs, the opposite of all the other gymnophthalmid species in which some kind of reduction occurs. More interestingly, the digits of Bachia species show an apparent loss of anterior-posterior patterning (Fig. 5 A,B). Digit identity can be determined in species with more developed limbs, but in cases of extreme reductions, no recognizable digit structure is left (Fig. 5C).

\section{Phylogenetic analysis}

Mapping the spectra of limb morphologies onto the gymnophthalmid subgroups reveals shared or independent origins for similar limb arrangements. In general, species that share similar limb morphologies are grouped together (Figs. 6,7). The limbs of Cercosaurini species are always pentadactyl. In the Ecpleopodinae, reduction affects dIV of the forelimb and $\mathrm{dV}$ of the hindlimb, and is restricted to the genera Anotosaura and Dryadosaura, which are nested within the group (Fig. 6). In the lineage that holds Rachisaurus, heterodactylinis, iphisiinis, and gymnophthalminis, reduction mostly affects digit I of the forelimb while the hindlimb is frequently pentadactylous (Fig. 6). Rachisaurus brachylepis and a few gymnophthalminispecies also show reduction in the hindlimbs. Bachia species exhibit a wide range of morphologies, but none of them show the typical pentadactyl arrangement.

The two lineages in which limb reduction resulted in even further losses of elements, the Gymnophthalmini and Bachiini, do not show a clear clustering of species with shared phenotypes (Fig. 7). One of the two main branches recognized among the Gymnophthalmini (Fig. 7) is comprised exclusively of the lacertiform Tretioscincus, Micrablepharus, Vanzosaura, and Procellosaurinus; while the other holds the lacertiform Gymnophthalmus and Psilophthalmus, and the snake-like Nothobachia and Calyptommatus (Gymnophthalmus is placed as a separate lineage by Castoe et al., 2004). Complete loss of digit I of the forelimb occurs in Psilophthalmus, Micrablepharus, Vanzosaura, and Procellosaurinus, yet Psilophthalmus does not group directly with the later three species. The snake-like gymnophthalminis Nothobachia and Calyptommatus, which represent the extremes of this subgroup regarding limb morphology, are always grouped together (the topology of Castoe et al., 2004, however, places Psilophthalmus in between them). The Bachiini (Fig. 7) show an even more puzzling situation, in which the diversity of limb arrangements follows no clear phylogenetic trend. The limiting amount of data available regarding both the anatomy and evolutionary relationships of Bachia species contribute to this confusing scenario.

\section{Analysis of gene expression in Calyptommatus sinebrachiatus}

We analysed the expression of Sonic hedgehog (Shh) in the fore and hindlimb buds of Calyptommatus sinebrachiatus embryos staged from 6 to 16 days of development (Fig. 8) comprising the early development of both fore and hindlimb buds. The forelimb bud develops until 9-10 days, and then its growth stops and the bud degenerates. The hindlimb bud, which does not degenerate and develops to a one-digit hindlimb, is already paddle-shaped at 16 days after laying, with femur, tibia, and fibula detected by cartilage staining (Roscito and Rodrigues, 2012a).

Sonic hedgehog mRNA was consistently observed in the no-
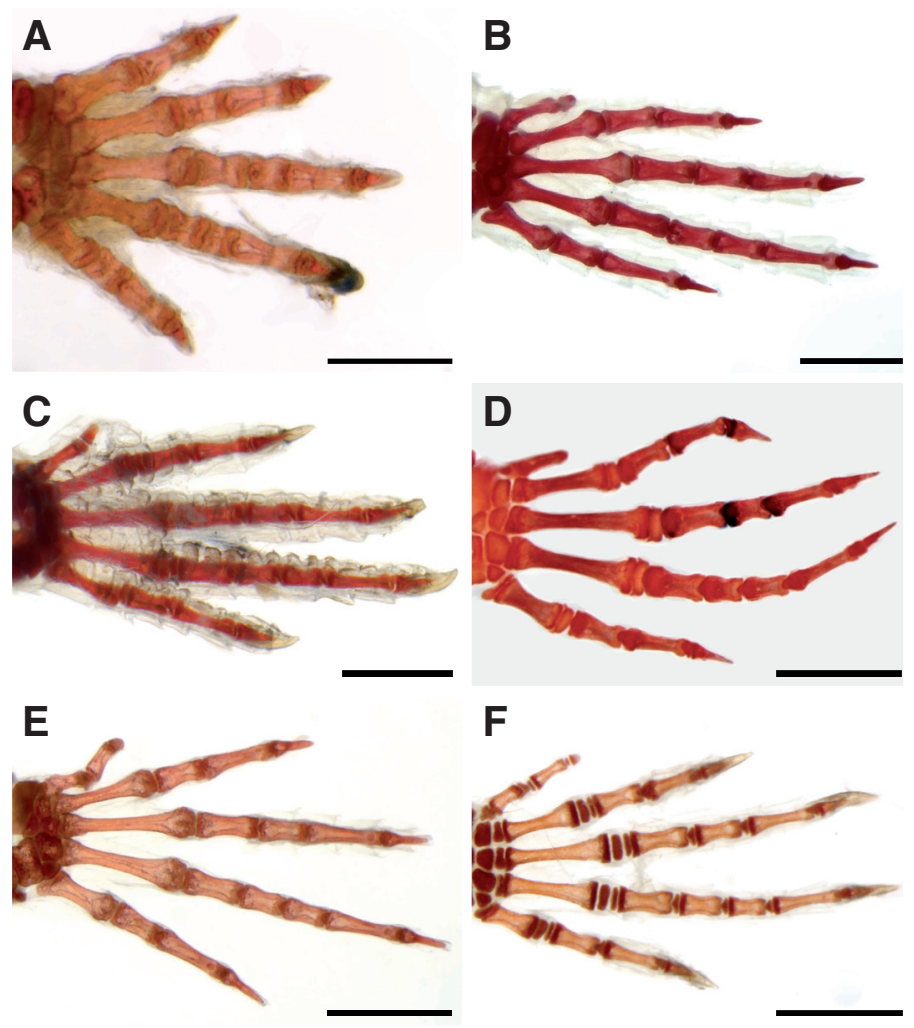

$\mathbf{F}$
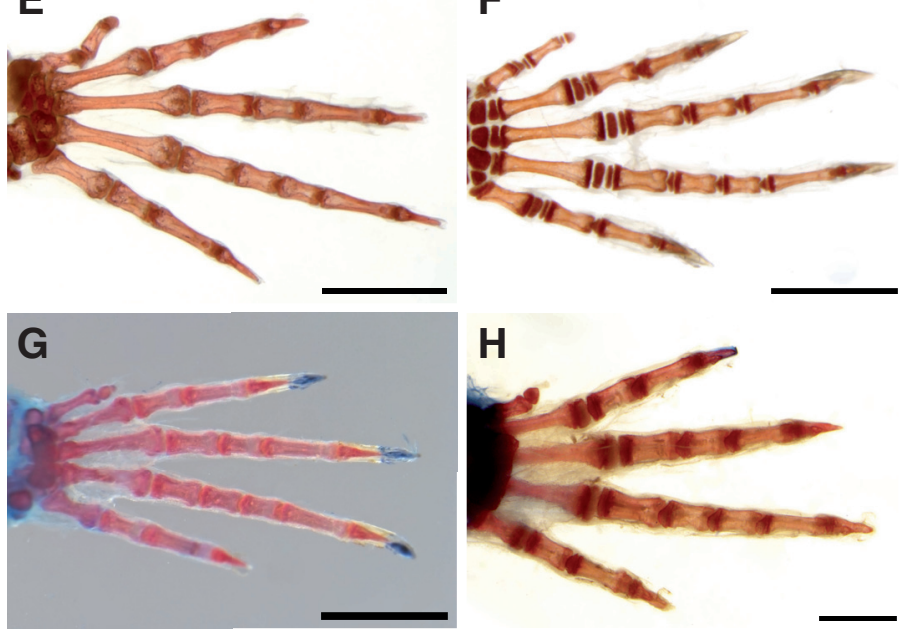

Fig. 3. Forelimb morphologies in gymnophthalmid species with minor limb reductions. Anotosaura vanzolinia (A); Colobodactylus dalcyanus (B); Colobodactylus taunayi MTR 00746 (C); Colobodactylus taunayi MZUSP 94254 (D); Colobosaura modesta (E); Stenolepis ridley (F); Heterodactylus lundii (G); Heterodactylus imbricatus (H). Digit I to the top. Scale bars: A, $0.5 \mathrm{~mm} ; B-H, 1.0 \mathrm{~mm}$. 
TABLE 1

SUMMARY OF THE PHALANGEAL FORMULAS FOR GYMNOPHTHALMIDAE SPECIES

\begin{tabular}{|c|c|c|c|c|}
\hline Species & $\begin{array}{l}\text { Hand } \\
\text { phalangeal } \\
\text { formula }\end{array}$ & $\begin{array}{l}\text { Foot } \\
\text { phalangeal } \\
\text { formula }\end{array}$ & Observations & References \\
\hline Acratosaura mentalis & (5) $2: 3: 4: 5: 3$ & (5) $2: 3: 4: 5: 4$ & Both fore and hindlimb follow the pentadactyl condition. & \\
\hline $\begin{array}{l}\text { Alexandresaurus } \\
\text { camacan }\end{array}$ & (5) $2: 3: 4: 5: 3$ & (5) $2: 3: 4: 5: 4$ & $\begin{array}{l}\text { Both fore and hindlimb follow the pentadactyl condition, but the last phalanx (ungual phalax) from dl in the } \\
\text { hand is shorter and ends in a relatively blunt end in comparison to the other four ungual phalanges, which } \\
\text { are longer and sharper. Rodrigues et al. (2007) mention that dl from forelimb bears no claw. }\end{array}$ & Rodrigues et al. (2007) \\
\hline Alopoglossus angulatus & (5) $2: 3: 4: 5: 3$ & (5) 2:3:4:5:4 & Both fore and hindlimb follow the pentadactyl condition. & \\
\hline Alopoglossus atriventris & (5) $2: 3: 4: 5: 3$ & (5) $2: 3: 4: 5: 4$ & Both fore and hindlimb follow the pentadactyl condition. Phalangeal formula following Grizante (2009). & Grizante (2009) \\
\hline Anotosaura collaris & (5) $2: 3: 4: 4: 3$ & (5) $2: 3: 4: 5: 3$ & $\begin{array}{l}\text { Osteology of the limbs described in Rodrigues et al. (2013); Kizirian and McDiarmid (1998) agree on the } \\
\text { phalangeal formula of the hindlimb. } \\
\text { The 5th phalanx from dIV of the forelimb, and the 4th phalanx of dV of the hindlimb, are absent. }\end{array}$ & $\begin{array}{l}\text { Kizirian and McDiarmid } \\
\text { (1998); Rodrigues et al. } \\
\text { (2013) }\end{array}$ \\
\hline Anotosaura vanzolinia & (5) $2: 3: 4: 4: 3$ & (5) $2: 3: 4: 5: 4$ & $\begin{array}{l}\text { Forelimb is short and stout, and the 5th phalanx from dIV is absent. The same condition is reported by } \\
\text { Kizirian and McDiarmid (1998). }\end{array}$ & Kizirian and McDiarmid (1998) \\
\hline Arthrosaura hoogmoedi & (5) $2: 3: 4: 5: 3$ & (5) $2: 3: 4: 5: 4$ & Both fore and hindlimb follow the pentadactyl condition. No osteological data presented in Kok (2008). & Kok (2008) \\
\hline Arthrosaura kockii & (5) $2: 3: 4: 5: 3$ & (5) $2: 3: 4: 5: 4$ & Both fore and hindlimb follow the pentadactyl condition. Phalangeal formula following Grizante (2009). & Grizante (2009) \\
\hline Arthrosaura reticulata & (5) $2: 3: 4: 5: 3$ & (5) $2: 3: 4: 5: 4$ & Both fore and hindlimb follow the pentadactyl condition. & \\
\hline Bachia barbouri & (2) $1 ?: 1 ?$ & (?) 0:0:0:0:0 & $\begin{array}{l}\text { Kizirian and McDiarmid (1998) did not determined the identity of the digits in the forelimb. } \\
\text { Hindlimbs are absent or tubercular (Dixon, 1973). } \\
\text { Kohlsdorf and Wagner (2006) reported the phalangeal formulas of 0:0:2:2:0 for the forelimb and 0:0:0:0:0 for } \\
\text { the hindlimb. }\end{array}$ & $\begin{array}{l}\text { Kizirian and McDiarmid } \\
\text { (1998); Dixon (1973); } \\
\text { Kohlsdorf and Wagner (2006) }\end{array}$ \\
\hline Bachia bicolor & (4) $0: 2: 2: 2: 2$ & (0) 0:0:0:0:0 & $\begin{array}{l}\text { Phalangeal formula following Kizirian and McDiarmid (1998) and Jerez and Tarazona (2009). Thomas (1965) } \\
\text { states the presence of } 1 \text { or } 2 \text { digits in the hindlimb. }\end{array}$ & $\begin{array}{l}\text { Kizirian and McDiarmid } \\
\text { (1998); Jerez and Tarazona } \\
\text { (2009); Thomas (1965) }\end{array}$ \\
\hline Bachia blairi & (5) $0: 2: 2: 2: 2$ & (5) $2: 2: 2: 0: 0$ & Phalangeal formula following Kizirian and McDiarmid (1998). & Kizirian and McDiarmid (1998) \\
\hline Bachia bresslaui & $\begin{array}{c}(2) \\
0: 0: 1 ?: 2 ?: 0\end{array}$ & (?) 0:0:0:0:0 & $\begin{array}{l}\text { Phalangeal formula following Kizirian and McDiarmid (1998). One cleared and double stained specimen was } \\
\text { available for analysis, but the forelimbs and right hindlimb were damaged; in the left hindlimb we could not } \\
\text { identify the elements distal to tibia/fibula. }\end{array}$ & Kizirian and McDiarmid (1998) \\
\hline
\end{tabular}

Bachia dorbignyi

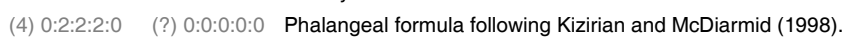

$\begin{array}{llll}\text { Bachia flavescens } & \text { (5) 0:1:1:1:0 } & \text { (3) 0:0:0:0:0 Due to poor condition of the specimen available for analysis, we cannot afirm that both fore and hindlimb were }\end{array}$ not damaged.

Forelimb with five metacarpals and one phalanx in each of the digits II, III, and IV.

The hindlimb was either less preserved, or not properly stained: the left hindlimb had only the femur, while in the right limb the zeugopodial elements (tibia/fibula) were clearly visible. The autopod was faintly stained, so the right limb the zeugopodial elements (tibia/fibula) were clearly visible. The autopod was faintly stained, so
we believe that the digits likely correspond to digits III, IV, and V, because of their position distal to the fibula. Our observations agree with Thomas (1965), which also reported three digits in the forelimb and no digits in the hindlimb of Bachia parkeri (which is now synonymized to B. flavescens, according to reptiledatabase.com). Kizirian and McDiarmid (1998), on the other hand, reported the phalangeal formula of (4) 0:2:2:2:0 and (4) 1:0:0:0:0 for fore and hindlimb, respectively, for Bachia flavescens parkeri.

Bachia heteropa

Bachia huallagana

(5) $1: 2: 3: 3: 2$ (?)/3 digits

Bachia intermedia

(4) 0:2:2:2:0

Bachia monodactylus monodactylus

Bachia pallidiceps

Bachia panoplia

(5) $0: 2: 2: 2: 2$

(4/5) 0:2:2:2:2

Bachia peruana

(?) 3 digits

Bachia pyburni

(5) $0: 3: 4: 4: 3$

Bachia scolecoides

(5) $0: 2: 2: 2: 2$

Bachia trisanale

Calyptommatus

leiolepis

Calyptommatus

nicterus

Calyptommatus

sinebrachiatus

Caparaonia itaiquara

(5) $2: 3: 4: 5: 3$

Cercosaura eigenmanni (5) 2:3:4:5:3

Cercosaura ocellata

(5) $2: 3: 4: 5: 3$

Cercosaura schreibersii (5) 2:3:4:5:3
(3) 0:0:1:1:0 (?) 0:0:0:0:0 Phalangeal formula following Kizirian and McDiarmid (1998).

dIV Osteology of the limbs described in Roscito and Rodrigues (2013).

Forelimb is absent externally, formed by a rudimentary humerus which does not protrude from the body wall. The single digit of the hindlimb is formed by one metatarsal and two phalanges (the last one being the ungual phalanx and bearing a nail).
Kizirian and McDiarmid (1998)

Kizirian and McDiarmid

(1998); Thomas (1965)

Kizirian and McDiarmid (1998)

Kizirian and McDiarmid

(1998); Dixon (1973)

Kizirian and McDiarmid

(1998); Thomas (1965); Dixon

(1973); Presch (1975)

Kohlsdorf and Wagner (2006)

Kizirian and McDiarmid (1998)

Kizirian and McDiarmid (1998)

Kizirian and McDiarmid (1998); Rodrigues et al. (2008)

Kizirian and McDiarmid (1998); Rodrigues et al. (2008)

Kizirian and McDiarmid (1998)

Roscito and Rodrigues (2013) 
TABLE 1 (CONTINUED)

SUMMARY OF THE PHALANGEAL FORMULAS FOR GYMNOPHTHALMIDAE SPECIES

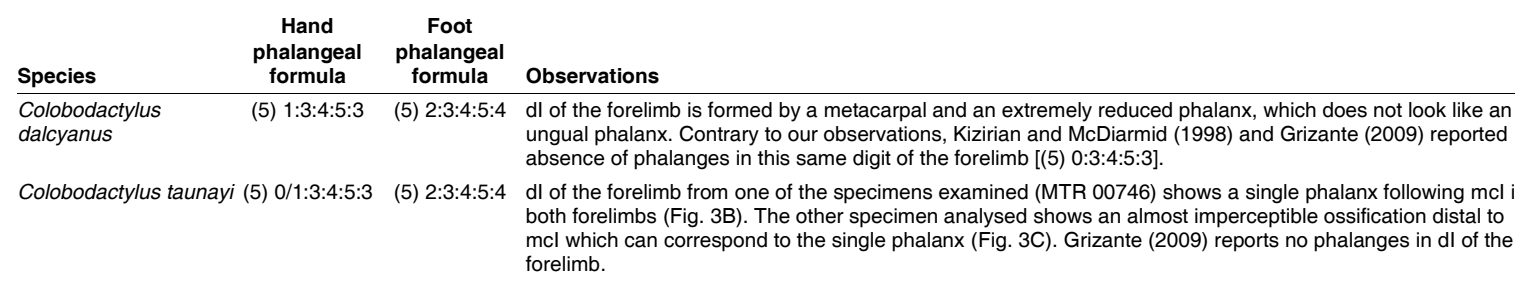

Colobosaura modesta

(5) $2: 3: 4: 5: 3$

Colobosauroides

cearensis

(5) $2: 3: 4: 5: 3$

Dryadosaura nordestina (5) 2:3:4:4:3

Echinosaura horrida

Gymnophthalmus

underwoodi

Heterodactylus

imbricatus

(5) $2: 3: 4: 5: 3$

(5) $1: 3: 4: 5: 3$

(5) $1: 3: 4: 5: 3$

(5) $2: 3: 4: 5: 4$

McDiarmid (1998) and Grizante (2009) agree with our observations regarding phalangeal formulas.

(5) 2:3:4:5:4 Both fore and hindlimb follow the pentadactyl condition. In specimen MZUSP 79595 we observed an asymmetry in phalange number between left and right forelimbs ( 4 or 5 phalanges in dIV).

(5) 2:3:4:5:4 Forelimb digits are short and the last phalanx of dIV is missing. Hindlimb follows the pentadactyl condition.

(5) 2:3:4:5:4 Both fore and hindlimb follow the pentadactyl condition.

(5) 2:3:4:5:4 dl of the forelimb is short, showing a single reduced phalanx. Hindlimb follows the pentadactyl condition.

Heterodactylus lundii $\quad$ (5) 1/2:3:4:5:3 $\quad$ (5) 2:3:4:5:4 Forelimb has a reduced dl. We observe an asymmetry between the left and right forelimbs, which show either

Heterodactylus lundii $\quad$ (5) 1/2:3:4:5:3 $\quad$ (5) 2:3:4:5:4 Forelimb has a reduced dl. We observe an asymmetry between the left and right forelimbs, which show either

(5) 2:3:4:5:4

are minor reductions in phalange number in both fore and hindlimb. The single phalanx from dl of the forelimb is reduced and does not resemble an ungual phalanx. The hindlimb follows the pentadactyl condition, although Kizirian and McDiarmid (1998) report only three phalanges in dV [(5)2:3:4:5:3] while we observed 4; Grizante (2009) agrees with our observation on phalangeal formula. one or two very small phalanges in this digit; the second phalanx seems vestigial. Hindlimb follows the pentadactyl condition.

pentadactyl condition.
Kizirian and McDiarmid (1988) report a single phalanx in dl of the forelimb, and also an asymmetry between left and right hindlimbs, which show either 3 or none phalanges in $\mathrm{dV}$ [(5) 2:3:4:5:3/0].

Iphisa elegans

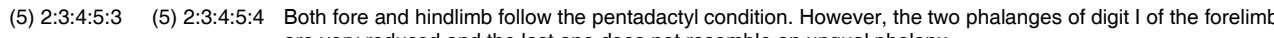
are very reduced and the last one does not resemble an ungual phalanx.

Leposoma guianensis

Leposoma osvaldoi

Leposoma

percarinatum

Micrablepharus

atticolus

Micrablepharus

maximiliani

Neusticurus bicarinatus

Neusticurus rudis

(5) Both fore and hindlimb

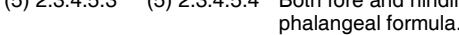

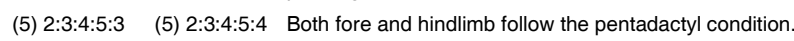

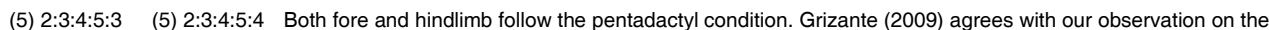
phalangeal formula.

$\begin{array}{lll}\text { (5) } 0: 3: 4: 5: 3 & \text { (5) 2:3:4:5:4 dl of the forelimb formed only by a very reduced } \mathrm{mcl} \text {; its proximal end is not flat as the other metacarpals }\end{array}$ showing a small bulge. Hindlimb follows the pentadactyl condition.

Nothobachia ablephara

(5) $2: 3: 4: 5: 3$

(5) $2: 3: 4: 5: 3$

dIV

(5) 2:3:4:5:4 Both fore and hindlimb follow the pentadactyl condition.

(5) 2:3:4:5:4 Both fore and hindlimb follow the pentadactyl condition. Phalangeal formula following Grizante (2009).

Pholidobolus montium

Placosoma cordylinum

Placosoma glabelum

Potamites ecpleopus

(former Neusticurus

ecpleopus)

Potamites juruazensis

(former Neusticurus

juruazensis)

Procellosaurinus

tetradactylus

Proctoporus bolivianus

Proctoporus xestus

(former Opipeuter

xestus)

Psilophthalmus

paeminosus

Ptychoglossus

brevifrontalis

Rhachisaurus

brachylepis

Scriptosaura catimbau

(5) $2: 3: 4: 5: 3$

(5) $2: 3: 4: 5: 3$

(5) $2: 3: 4: 5: 3$

(2) 0:0:2:4:0 A single digit is present in the forelimb, with one metacarpal and two phalanges, the last one, the ungual phalanx, bearing a nail. The hindlimb is formed by two digits, identified as digits III and IV.

(5) 2:3:4:5:4 Both fore and hindlimb follow the pentadactyl condition.

(5) 2:3:4:5:4 Both fore and hindlimb follow the pentadactyl condition. Phalangeal formula following Grizante (2009).

(5) 2:3:4:5:4 Both fore and hindlimb follow the pentadactyl condition.

(5) 2:3:4:5:4 Both fore and hindlimb follow the pentadactyl condition.

$\begin{array}{lll}\text { (5) } 2: 3: 4: 5: 3 & \text { (5) } 2: 3: 4: 5: 4 & \text { Both fore and hindlimb follow the pentadactyl condition. Phalangeal formula following Grizante (2009). }\end{array}$

(5) $0: 3: 4: 5: 3$

(5) 2:3:4:5:4 Osteology of the limbs described in Roscito and Rodrigues (2013). $\mathrm{dl}$ of the forelimb is represented by a very reduced mcl; hindlimb follows the pentadactyl condition.

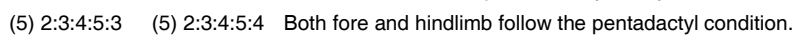

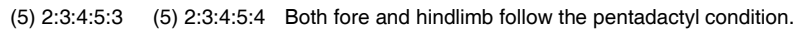

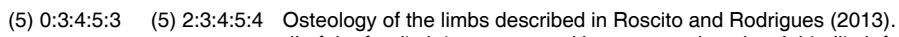
$\mathrm{dl}$ of the forelimb is represented by a very reduced $\mathrm{mcl}$; hindlimb follows the pentadactyl condition.

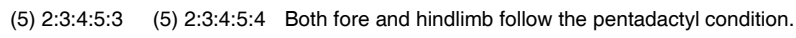

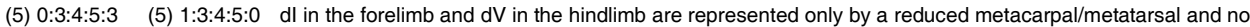
phalanges. Kizirian and McDiarmid (1998) agree on the phalangeal formula.

Humeurs + dIV Osteology of the limbs described in Roscito and Rodrigues (2013).

distal element

Forelimb absent externally, represented by a rudimentary humerus and a vestigial ossification distal to it.

The hinflimb has a single digit, which is formed by one metatarsal and one phalanx which does not bear a nail.

Stenolepis ridley

(5) $2: 3: 4: 5: 3$

Tretioscincus agilis

(5) $2: 3: 4: 5: 3$ $\begin{array}{ll}\text { (5) } 2: 3: 4: 5: 4 & \text { Both fore and hindlimb follow the } p \\ \text { reduced and does not bear a nail. }\end{array}$ $\begin{aligned} \text { (5) } 2: 3: 4: 5: 4 & \text { Both fore } \\ & \text { reduced. }\end{aligned}$

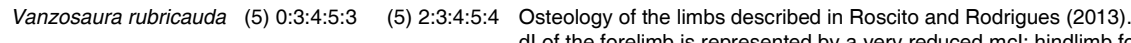
$\mathrm{dl}$ of the forelimb is represented by a very reduced $\mathrm{mcl}$; hindlimb follows the pentadactyl condition.

References

Kizirian and McDiarmid

(1998); Grizante (2009)

Grizante (2009)

Kizirian and McDiarmid

(1998); Grizante (2009)

Kizirian and McDiarmid

(1998); Grizante (2009)

Kizirian and McDiarmid (1998)

Grizante (2009)

Grizante (2009)

Gizante (2009)

.

Entries in grey correspond to those species not directly analyzed. dc, distal carpal; mc, metacarpal. 
A
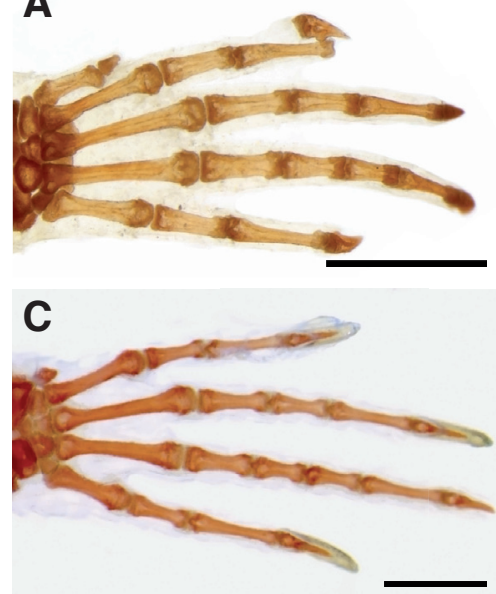

E
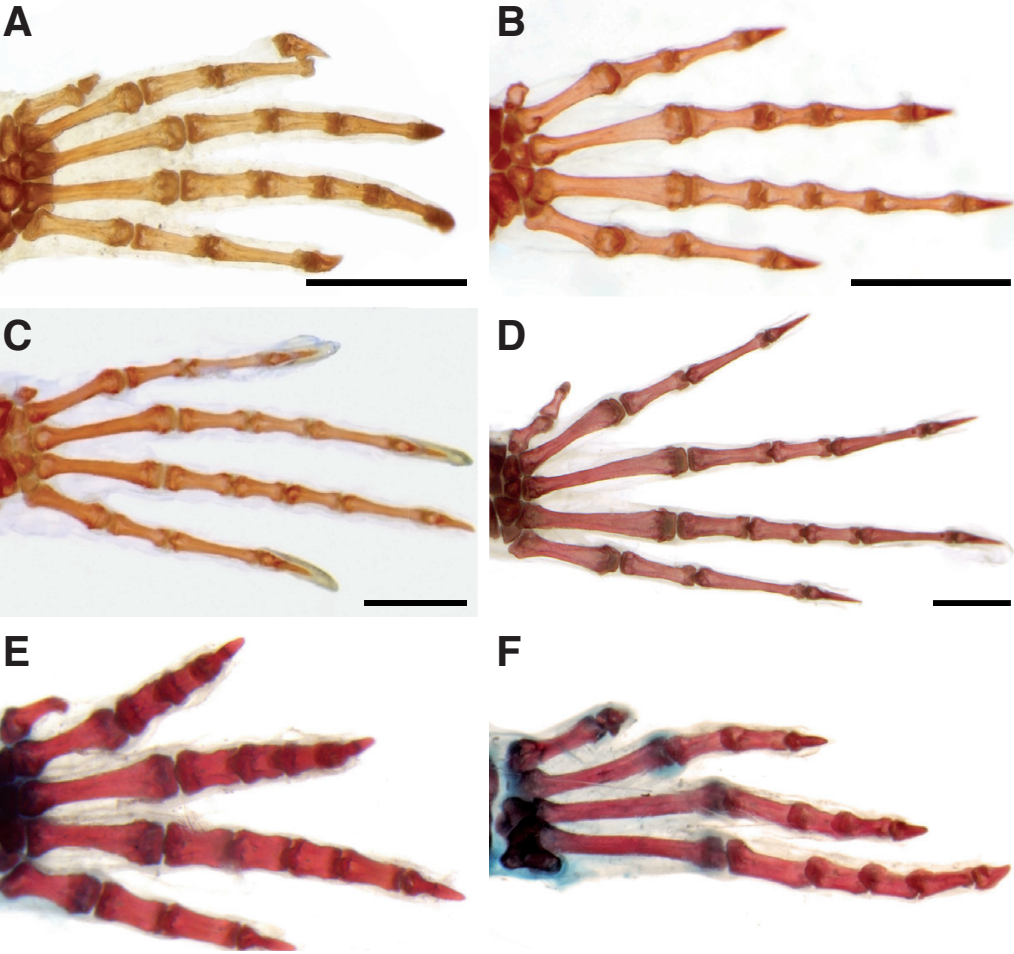

$\mathbf{F}$

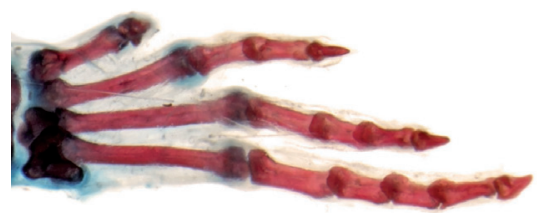

Fig. 4. Limb morphologies in gymnophthalmid species with minor limb reductions. Gymnophthalmus underwoodi forelimb (A); Micrablepharus atticolus (B); Psilophthalmus paeminosus (C); Tretioscincus agilis (D); Rachisaurus brachylepis (E,F). Digit I to the top. Scale bars: A, B,D,F, $1.0 \mathrm{~mm}$; $, E, 0.5 \mathrm{~mm}$

tochord of all embryos (Fig. 8 A,C,E,H; images in detail). However, it was not detected in the forelimb at any of the stages analysed. In contrast, Shh it was detected in the posterior mesenchyme of the hindlimb bud of the 16-day old embryo (Fig. 8K), the oldest stage analysed.

\section{Discussion}

Patterns of limb reduction in the Gymnophthalmidae

Limb reduction has evolved repeatedly in squamates, with almost every major group showing the loss of one or more bones in the limbs. The situation is no different among the Gymnophthalmidae, with all but three groups exhibiting loss of one or more phalanges (Fig. 1).

Minor reductions, involving the loss of one or two phalanges, account for the majority of cases of limb reduction among the gymnophthalmids. Digit I of the forelimb is the most affected: out of the 10 genera analysed that show these minor losses, 8 have lost phalanges in dl. When a single phalanx is lost, the remaining phalanx is very reduced in size, while the size of the metacarpal seems comparable to that of the other metacarpals. In contrast, when both phalanges
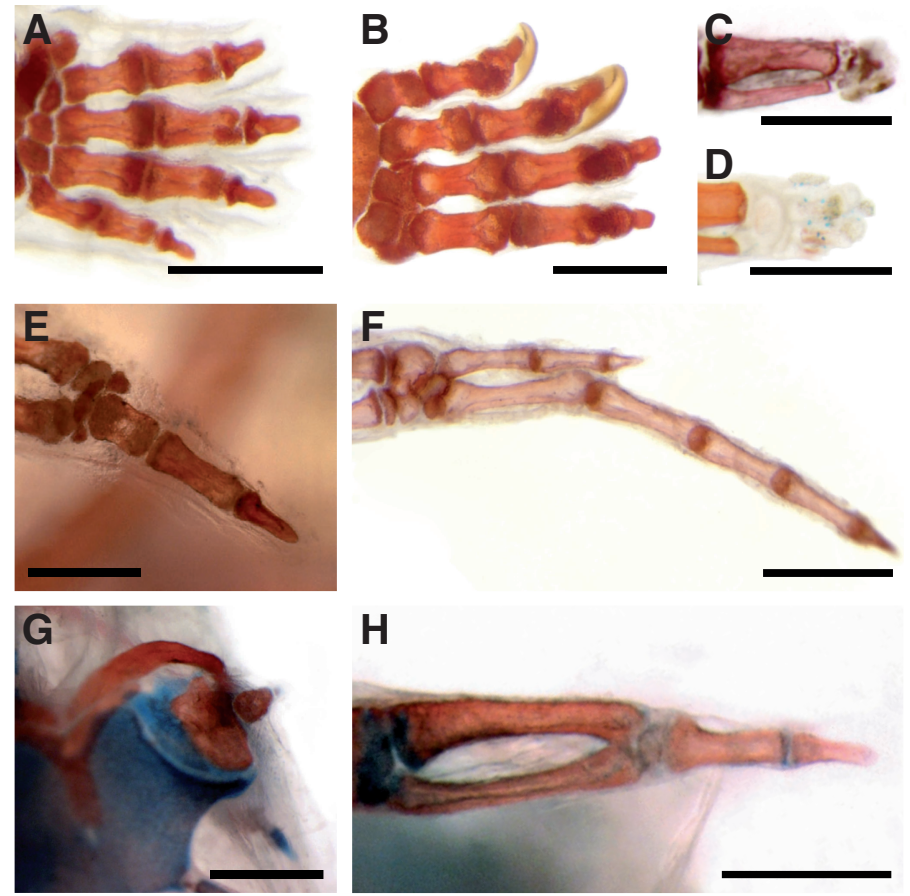

H
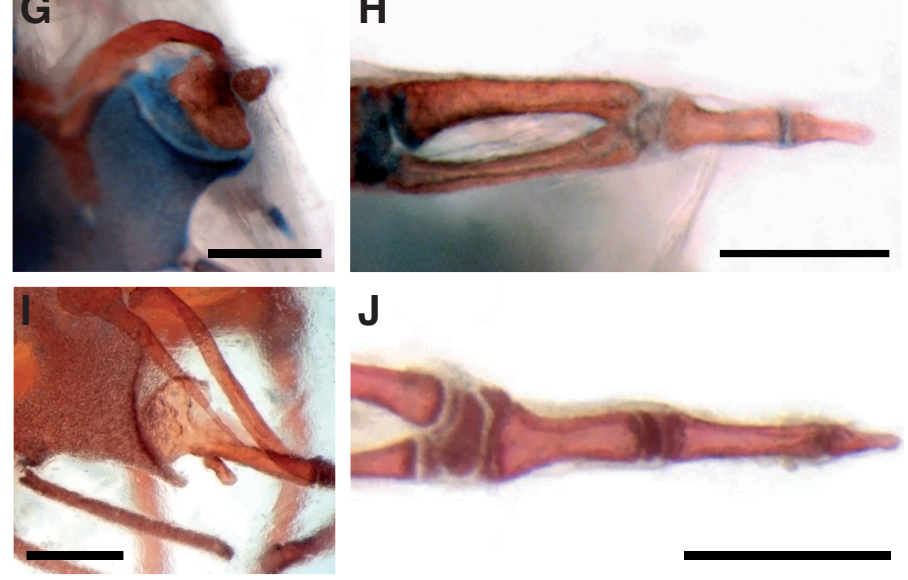

$\mathbf{J}$

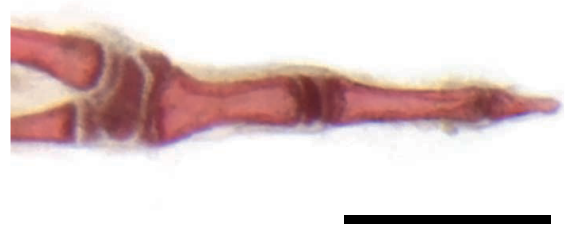
are absent, $\mathrm{mcl}$ is reduced to a vestigial element. Phalanx loss is also seen in dIV of the forelimb, but with a lower frequency when compared to losses in dl. This scenario contrasts the observations of Greer (1991), that has shown that dIV is more likely to be affected when losses occur in a single digit from the forelimb (26 times), followed by dl (6 times), and last, by dV (only 1 case).

Losses of phalanges in either dI or dIV of the forelimb seem to be specific to distinct lineages: loss in dl is seen in the Rachisaurinae, Heterodactylini, Iphisiini and Gymnophthalmini, while loss of dIV occurs only in some species of the Ecpleopodinae. However, Rodrigues et al., (2013) have recently described a new Leposoma species, L. sinepollex that, as the name suggests, lacks dl of the forelimb. Furthermore, the closely-related $L$. nanodactylus is reported to have a shorter dl of the forelimb (Rodrigues 1997; Rodrigues et al., 2013). These observations break down the notion of clade-specific types of reduction, since Leposoma are nested within the Ecpleopodinae, a group characterized by reductions affecting dIV of the forelimb. Furthermore, it shows that the scincoides lineage of the Leposoma genus, to which $L$. nanodactylus and $L$. sinepollex are allocated, represents one more independent instance of digit reduction among the gymnophthalmids (Rodrigues et al., 2013). A second event of loss of dl of the forelimb among the Ecpleopodinae is seen in the monotypic Amapasaurus tetradactylus (Cunha, 1970; pers. obs.). This species seems to be more related

Fig. 5. Limb morphologies in gymnophthalmid species with the greatest degrees of limb reduction. Bachia panoplia fore (A) and hindlimb (B) Bachia bresslaui hindlimb (C); Bachia flavescens hindlimb (D); Nothobachia ablephara fore (E) and hindlimb (F); Scriptosaura catimbau fore (G) and hindlimb (H); Calyptommatus leiolepis forelimb (I); Calyptommatus sinebrachiatus hindlimb (J). Digit I to the top. Scale bars: A-C, F, G, I-J, 0.5 $\mathrm{mm} ; D, E, H, 0.25 \mathrm{~mm}$. 
to the parietale group of Leposoma (Rodrigues and Ávila-Pires, 2005), which holds the two Leposoma species analysed here ( $L$. percarinatum and $L$. osvaldoI), none of which showing any kind of limb reduction. If this relationship is confirmed, then Amapasaurus represents yet another independent event of limb reduction within the group.

Interestingly, these minor losses in the forelimb are not accompanied by losses in the hindlimbs, which still maintain the ancestral phalangeal formula. The exceptions are Anotosaura collaris, which has lost a single phalanx from dV, and Rachisaurus brachylepis, which has lost the entire $\mathrm{dV}$ but the corresponding metatarsal. In general, $\mathrm{dV}$ of the hindlimb is the digit that accounts for the most cases of reduction (Greer, 1991; Shapiro et al., 2007), although losses of all phalanges from dV usually co-occur with complete loss of dl (Shapiro et al., 2007), which is not the case for Rachisaurus.

The effect of intrapopulational variation on the number of phalanges lost in both fore and hindlimb, as previously observed in Bachia and Hemiergis (Dixon, 1973; Choquenot and Greer, 1989), cannot be estimated based on our sampling because most of it consists of a single individual per species. The observation of two specimens of Colobodactylus taunayi with a different configuration of $\mathrm{dl}$ of the forelimb - depending on how the vestigial ossification seen in individual MZSUP 94254 (Fig. 3D) is interpreted, specimens either differ in the number of phalanges, or in the morphology of the single phalanx - argues in favor of the need for increased sampling in order to understand the morphology of reduced limbs and its dominant pattern within aspecies. On the other hand, we have analysed several individuals of Vanzosaura rubricauda, Psilophthalmus paeminosus, and Procellosaurinus tetradactylus and none of those showed any variation in number of phalanges. The extent to which this variability in the number of phalanges represents a clade-specific flexibility, some kind of developmental constraint related to how reduced is the digit, or a simple factor of chance in our sampling, will unfortunately remain unknown until increased sampling and more detailed anatomical studies are done.

Major limb reductions are seen in two other gymnophthalmid groups: the Gymnophthalmini, with Nothobachia, Calyptommatus, and Scriptosaura (Rodrigues and dos Santos, 2008), and the genus Bachia. In such severe cases of limb reduction, especially regarding losses of multiple limb elements to an almost limblessness state, the remaining skeletal elements (if any) are vestigial and frequently show some kind of loss of anatomical information. This is the case for the vestigial humerus of Calyptommatus and Scriptosaura; the small elements seen laterally to the forelimb digits of Nothobachia and in the hindlimb of Calyptommatus, which cannot be identified only based on the adult morphology (Fig. 5A, J); and the vestigial elements in Bachia bresslaui hindlimb (Fig. 5C, D).

On the other hand, the skeletal elements present in "intermediate forms" usually retain anatomical features and may still maintain topological relations to neighboring elements. This is the case for the hindlimb of Nothobachia ablephara, in which the two remaining digits can be identified as dIII and dIV based on their relations to the tarsal elements (Roscito and Rodrigues, 2013). Remarkably, digits and phalanges in Bachia seem to be deprived of anatomical information, in the sense that all digits - even in species with high number of digits, look similar to each other.

Two major patterns of limb reduction can be recognized among those Gymnophthalmid lizards that show some degree of limb reduction, whether it is a loss of a single phalanx or the loss of essentially the entire limb. In all species but Bachia, reduction of the forelimb is always more advanced than reduction in the hindlimb; Bachiashows an opposite trend. The first case, in which the forelimb is more reduced than the hindlimb, is the most frequent pattern in limb-reduced squamates, while the second case is only seen in Bachia, in one scincid and one teiid, and in the amphisbaenid

\section{CERCOSAURINI}

All species have pentadactyl limbs.

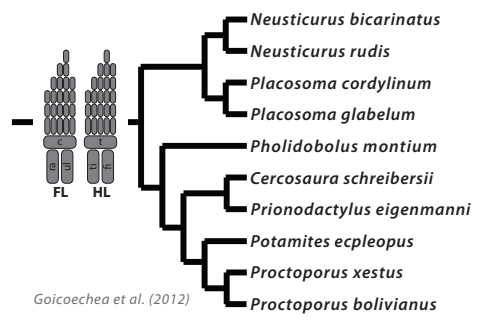

HETERODACTYLINI

Reduction in size (or loss) of the last phalanx from digit I of the forelimb.

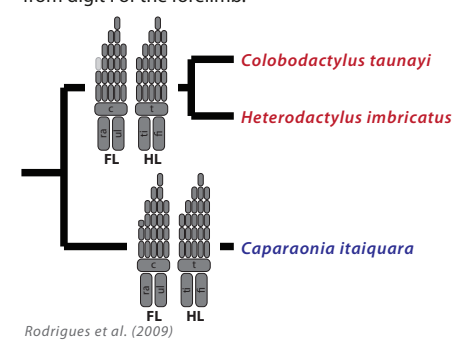

Fig. 6. Evolutionary relationships within the Cercosaurini, Heterodactylini, Iphiisini, and Ecpleopodinae subgroups, with a representation of the different limb morphologies observed in each species/groups of species. Limb skeletal elements present in the limbs are colored dark grey, and those that are absent (in reference to the generalized pentadactyl condition) are colored light grey. Species names in black indicate those species that have fully pentadactyl limbs; names in blue indicate those species that also have pentadacatyl limbs but show reduction in size of one or more phalanges; names in red indicate species that have lost one or more phalanges in relation to the pentadactyl condition. FL/HL, forelimb/hindlimb; ra, radius; ul, ulna; c, carpus; ti, tibia; fi, fibula; $t$, tarsus.

\section{IPHISIINI}

All species have pentadactyl limbs, but show reduction in size of the last phalanx from dl of the forelimb.

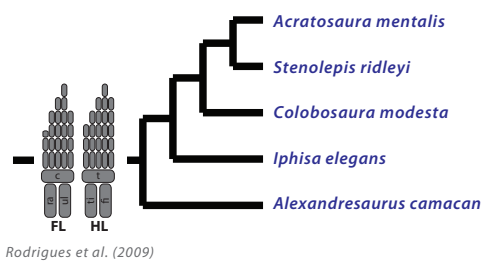

ECPLEOPODINAE

Most species have pentadactyl limbs; loss of individual phalanges in Anotosaura and Dryadosaura.

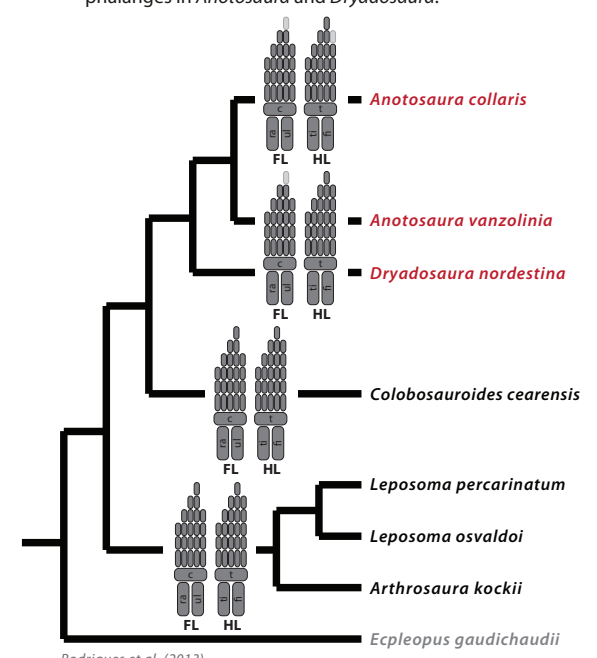


genus Bipes (Brandley et al., 2008). As every 'rule' has its exception, two recently described Bachia species ( $B$. micromela and B. psamophila; Rodrigues et al., 2007) have the forelimbs more reduced than the hindlimbs. Although no osteological data was presented for either species, the representations clearly show that the hindlimb is more developed than the forelimb (both in length and in number of digits, in the case of B. psamophila).

In addition, reduction in the fore and hindlimbs of Bachia seem to follow distinct patterns: reduction in the forelimb has, apparently, an anterior predominance (dl usually reduced or absent), while in the hindlimb, $\mathrm{dV}$ is the most affected. Reduction/loss of dl of the forelimb is common among limb-reduced forms (75\% of the cases; Shapiro et al., 2007). Furthermore, there is no correlation between reduction/loss of this digit with reduction/loss of any of the other digits, meaning dl is relatively independent. Reduction in $\mathrm{dV}$ of the hindlimb is also common ( $90 \%$ of the cases; Shapiro et al., 2007), and seems to be highly correlated with corresponding reduction in dl of the hindlimb $(73 \%)$. Digit $V$ is lost in the hindlimbs of $B$. panoplia, B. scolecoides, and B. heteropa, but $\mathrm{dl}$ is complete (2 phalanges) in all three species. This predominant reduction of the post-axial side of the limb, with maintenance of the pre-axial side, resembles the pattern seen in archosaurs fore and hindlimbs (Shapiro et al., 2007) and in anurans (Shubin and Alberch, 1986). In addition, a few Bachia species such as B. panoplia, B. scolecoides, $B$. intermedia, B. bicolor, and B. dorbignyi, show morphologically similar digits with uniform phalangeal numbers, resembling what is seen among the turtles and in some archosaurs (Shapiro et al., 2007). These opposing modes of digit reduction between fore and hindlimbs of Bachia suggest that different developmental mechanisms may be coming into play. Unfortunately, the lack of a detailed anatomical analysis of the genus is a drawback to further hypothesis on limb development.

\section{Developmental biology of reduced limbs}

\section{Morphological perspective}

The development of the tetrapod limb is a complex process that requires precise spacial and temporal coordination of many signaling molecules, resulting in the differentiation of an initially homogeneous population of cells into the different tissues that form the limbs.

One of those tissues, the limb skeleton, arises from pre-cartilaginous primordia that are formed in a proximal-distal direction. In amniotes, the order of appearance of limb

\section{GYMNOPHTHALMINI}

\section{BACHIINI}

Varied degrees of limb reduction. skeletal elements seems to be remarkably conserved, despite the major differences in limb morphology across species. Comparative analyses have shown that the pre-cartilaginous elements form following a primary axis of development that runs through the humerus/femur, ulna/fibula, distal carpal/tarsal IV, and digit IV; the remaining digits usually form following the sequence III $>$ II/V $>$ I (Shubin and Alberch, 1986). This generality holds true for the squamates analysed so far (Howes and Swinnerton, 1901; Mathur

Reduction in size or loss of phalanges from dl of the forelimb.

Major reductions in fore and hindlimb in Nothobachia and Calyptommatus.
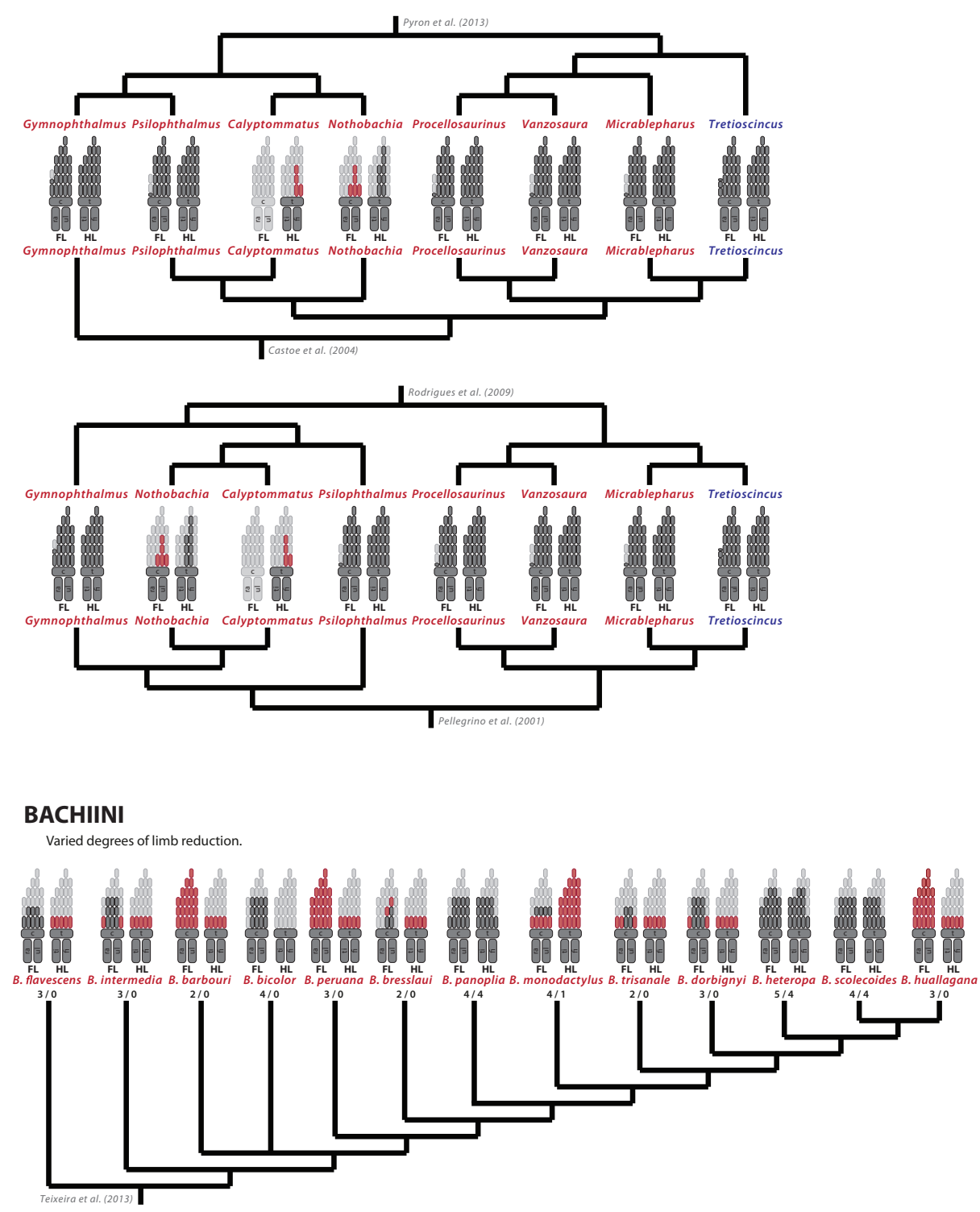

Fig. 7. Evolutionary relationships within the Gymnophthalmini and Bachiini subgroups, with a representation of the different limb morphologies observed in each species. Limb skeletal elements present in the limbs are colored dark grey, those that are absent (in reference to the generalized pentadactyl condition) are colored light grey, and those with uncertain identity are in red. Species names colored in blue indicate those species that have pentadacatyl limbs but show reduction in size of one or more phalanges; names in red indicate those species that have lost one or more phalanges in relation to the pentadactyl condition. FL/HL, forelimb/hindlimb; ra, radius; ul, ulna; c, carpus; ti, tibia; fi, fibula; $t$, tarsus. 
and Goel, 1976; Rieppel, 1994; Shapiro, 2002; etc).

Another generality derived from the analysis of limb-reduced species is that losses, or reduction, of limb elements, affect elements which are formed last in development. In the case of digits, loss follows the order I > V/II > III/IV (Morse, 1872; Lande, 1978; Greer, 1987; 1991; Shapiro et al., 2007). This scenario could imply that losses of elements that are not essential for the development of other elements could take place more easily than loss of those elements that form the primary axis of the limb. The apparent constraint against the loss of the central digits (III and IV) could also be related to the role that these digits play in hand/foot stability during locomotion (Greer, 1991), but we still lack a detailed and comparative knowledge of how hand/feet width and length could influence on locomotion performance.

The prevalence of the primary axis, and the relative common sequence of digit development would allow, in principle, to identify the reduced digits of Calyptommatus, Scriptosaura, and Nothobachia as the most central digits: those in Nothobachia hindlimb would be identified as dIII and dIV, and the single digit in Nothobachiaforelimb and in Calyptommatus and Scriptosaura hindlimbs would be identified as dIV. However, the number of phalanges in these digits would not match that of the corresponding digit of a generalized pentadatyl limb.

The first question that stems from this observation is if these apparently incomplete digits would be the product of an early termination of limb bud development. If so, we should expect to find a similar digit/ phalangeal configuration in a developmental stage of a pentadactyl limb bud (see Shapiro, 2002). However, this is not the case for neither species, arguing against a truncation mechanism to explain the resulting limb morphology.

In contrast, there are cases in which the adult phalangeal arrangement corresponds to the arrangement seen in a particular developmental stage, thus reflecting that the reduction process was likely the result of a truncation of embryonic development. Interestingly, this is usually seen in species which have lost only a few phalanges. This is the case for Hemiergis initialis (Shapiro, 2002), and several other skinks, agamids, cordylids and gekkonids that show minor losses of one or two terminal phalanges of digits IV and V (Greer, 1991; Russel and Bauer, 2008); among the gymnophthalmids, Anotosaura shows a phalangeal configuration resembling that of a late developmental stage of Calotes versicolor (Mathur and Goel, 1976).

Digit configurations seen in some Bachia species, such as $B$. panoplia, $B$. scolecoides, and $B$. bicolor also do not seem to correspond to truncations of a pentadactyl embryonic developmental program. On the other hand, the forelimbs of $B$. bresslaui, $B$. trisanale, and $B$. heteropa resemble stages of development of other squamates

(Shapiro et al., 2007), and could possibly have originated from truncations of development.

\section{Molecular signaling perspective}

The understanding of the signaling network that controls limb growth and patterning during embryonic development sheds light on the possible mechanisms by which a limb becomes reduced. Labinduced mutations or alterations of individual signaling pathways result in a variety of limb phenotypes, some of which may resemble those seen in natural populations. Furthermore, the development of genetic and molecular tools facilitates the investigation of a wider diversity of species other than the commonly studied chicken and mouse. This increasing knowledge helps to direct investigations on species never so far studied.

Multiple signals interact to control both the growth and patterning of the developing limb. Changes in such system can affect growth, but not the overall pattern (scaling), or can affect the pattern itself (and, hence, localized growth) and result in a different configuration of the skeletal elements.

The forelimb of Dryadosaura looks like the result of a scaling process of limb autopod, since the phalanges are much shorter in comparison to those of the hindlimb, and of the forelimbs of similar-sized gymnophthalmids. However, Dryadosaura has also lost a single phalanx, a condition seen in many other Gymnophthalmids. These asymmetric losses of phalanges reflect some kind
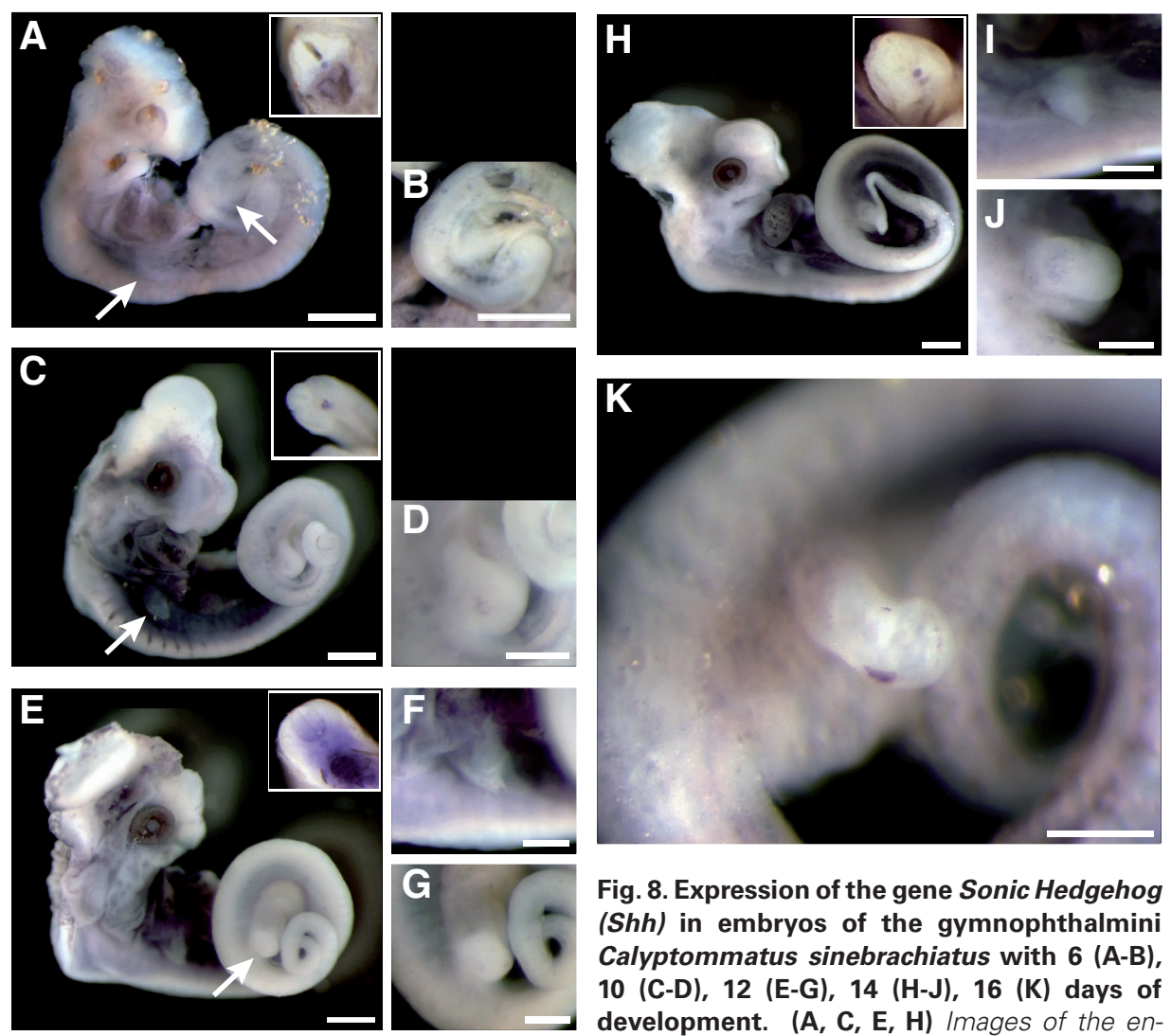

Fig. 8. Expression of the gene Sonic Hedgehog (Shh) in embryos of the gymnophthalmini Calyptommatus sinebrachiatus with 6 (A-B), 10 (C-D), 12 (E-G), 14 (H-J), 16 (K) days of development. (A, C, E, H) Images of the entire embryo: arrows in (A) point to the fore and hindlimb, arrow in (C) points to the forelimb, and arrow in (E) points to the hindlimb; the images in detail on the upper right corner represent a transversal cut at mid-trunk showing positive staining in

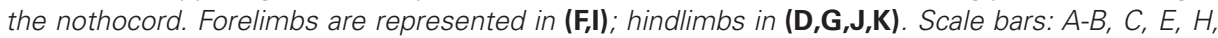
$0.5 \mathrm{~mm} ; D, F, G, I, J, K, 0.25 \mathrm{~mm}$. 
of deviation from the common developmental pattern other than a simple scaling mechanism, which should, in principle, affect all digits equally.

Digits form from single cartilaginous condensations in the autopod, which are separated from each other by interdigital spaces. The condensations elongate and segment into phalanges, and the distal-most phalanx differentiates into the ungueal phalanx. Growth of the digit cartilaginous condensation is controlled by FGF8 signaling from the apical ectodermal ridge (AER), which along with WNT signaling from the ectoderm, maintain the distalmost cells in an undifferentiated, proliferative state (Stricker and Mundlos, 2011). BMPs from the mesenchyme are important positive regulators of chondrogenesis. Downregulation in either FGF8 or BMP signaling results in shorter cartilaginous condensations and, frequently, in brachydactyly phenotypes (reduced size or loss of phalanges; Sanz-Esquerro and Tickle, 2003; Stricker and Mundlos, 2011). Conversely, over expression of FGF8 results in increased growth of the digit condensations, and in the formation of additional phalanges in the chicken limb (Sanz-Esquerro and Tickle, 2003).

In this scenario, minor spatial and temporal modulations of FGF8 or BMP expression could account for the formation of a reduced number of phalanges, or shorter ones, in the gymnophthalmids analyzed here and also in other tetrapods with reduced limbs. Furthermore, the predominance of loss/reduction in the lateralmost digits ( $\mathrm{dl}$ and dV), a common trend among squamate reptiles (Greer, 1991; Shapiro et al., 2007), could be easily explained by a possible antero-posterior shortening of the extension of the AER, which would put the lateral-most digits under the influence of smaller amounts of FGF signaling. In fact, shortening of the AER is likely one of the mechanisms that contribute to the reduction of dll and dV of some mammals (Cooper et al., 2014; Lopez-Rios et al., 2014).

In contrast, the rarer loss of the terminal phalanx from digit IV (seen here only in Anotosaura species) could be explained by an early termination of AER-derived signaling, which would lead to the truncation of the normal developmental sequence. This hypothesis is supported by experimental manipulations in chicken limbs, in which early interruption of FGF signaling result in the loss of terminal phalanges and in the premature induction of the digit tip developmental program (Sanz-Esquerro and Tickle, 2003). The modulation between lower FGF signaling and the switching on of the "tip developmental program", which involves Wnt signaling, explains the presence of the ungueal phalanx in those digits with reduced number of phalanges. Furthermore, the ungueal phalanx from dIV is the last one to form in development (Mathur and Goel, 1976; Shapiro et al., 2007), hence, would be the first one lost following an early termination of FGF signaling.

Signaling from the AER promotes mesenchymal cell proliferation and limb outgrowth; inhibition of FGF8 and FGF4 at different developmental stages leads to progressive loss of elements along the proximo-distal axis, and the complete knockdown of these FGFs results in failure of limb formation (Lewandoski et al., 2000; Sun et al., 2002; Dudley et al., 2002). Downregulation of AER signaling reduces cell proliferation, resulting in skeletal defects due to the smaller number of cell progenitors. Raynaud (1990) showed that inhibition of DNA synthesis results in a reduction of the number of digits formed in the limbs of the pentadactylous lizard Lacerta viridis, and that the earlier the treatment, the more digits we missing. More interestingly, the digits most frequently affected (lost) were $\mathrm{dl}$ and $\mathrm{dV}$ and those most frequently retained were dIII and dIV, which corresponds to the naturally occurring patterns described previously (Greer, 1991; Shapiro et al., 2007).

A premature downregulation of FGFs from the AER and the consequent truncation of the developmental pathway could also explain the morphology of the forelimb of Bachia heteropa, which has a phalangeal arrangement (1.2.3.3.2) similar to that seen in a developmental stage of Hermiergis initialis (Shapiro, 2002). However, the arrangement of $B$. heteropa hindlimb (2.2.3.3.0) is not paralleled by any developmental stage of any squamate studied so far, although it is similar to a developmental stage of the newt Ambystoma (Alberch and Gale, 1985).

The uniform phalangeal number seen in most Bachia species (1-2 phalanges in at least 3 digits) could be the result of truncations of the developmental program coupled with additional mechanisms directing the loss of lateral-most digits - as for example the already-mentioned antero-posterior shortening of the AER and of the signaling derived from it.

The homogeneity of both size and morphology of the digits of those Bachia species led Kohlsdorf and Wagner (2006) to suggest a correspondence of these arrangements with the phenotype resulting from mouse knockout mutants for Gli3. This mesenchymal transcription factor, together with Sonic hedgehog from the ZPA (zone of polarizing activity), are key players in the antero-posterior polarization of the developing limb bud (Wang et al., 2000; Litingtung et al., 2002; te Welscher et al., 2002); their antagonistic interactions determine a signaling gradient along the AP axis of the limb bud over which digit number and identity are laid down (Litingtung et al., 2002). Limbs that develop in the absence of Gli3 are polydactylous, and the resulting digits have 2 phalanges each and seem identical ("appear more serially homologous than in the wild type"; Litingtung et al., 2002). Although we don't know the developmental mechanisms responsible for the limb phenotypes seen in Bachia, it sounds unlikely that some sort of downregulation of Gli3 could account for these arrangements: a reduction in the amount of Gli3 would imply an anterior expansion of Shh expression, which would result, most likely, in some degree of polydactyly.

Loss or downregulation of Shh, on the other hand, could explain the limb morphologies of Nothobachia and Calyptommatus. Progressive inactivation of Shh expression from mouse limb buds leads to a corresponding progressive loss of digits (Zhu et al., 2008), with more digits being lost the earlier Shh is inactivated. The same effect was observed in scincid lizards from the genus Hemiergis with different limb morphologies: reduction in the number of digits seems to be caused by a reduction in the duration of Shh expression; the more reduced the limb, the less time Shh is present in the limb buds (Shapiro et al., 2003). Shh maintains a positive feedback loop with growth-promoting FGFs from the AER via Gremlin signaling (Laufer et al., 1994; Niswander et al., 1994; Zuniga et al., 1999; Lewandoski et al., 2000; Sun et al., 2002); thus, decrease in Shh expression is always correlated with a decrease in cell proliferation, resulting in a smaller limb bud (Chiang et al., 2001; Shapiro et al., 2003) and, consequently, in less progenitor cells.

Determining the identity of digits present in partially or greatly reduced limbs can be quite difficult. Even though one might rely on the primary axis generalization, reduced limbs/digits can show 
a high degree of anatomical divergence from the ancestral condition, often resulting in controversial homology assignments; one of the greatest examples is the over 150-year old debate over the identity of the digits in the chicken wing (reviewed in Young et al., 2011). Therefore, integrating morphological and molecular evidences is essential for the elaboration of an evolutionary scenario to accommodate the divergent observations (for example, Young et al., 2009).

As discussed before, from the morphological point of view, multiple embryological evidences (Shubin and Alberch, 1986; Müller and Alberch, 1990; Chiang et al., 2001; Noro et al., 2009; Young et al., 2009; Leal et al., 2010; Shapiro, 2002, and many others) show that: i) the condensation corresponding to dIV is the first one to form in the limb buds; ii) digits most often form sequentially in a posterior-anterior order (IV>III $>$ II/V>I; although Zhu et al., 2008 evidences claim for more detailed observations of digit development); and iii) that digits are lost in the reverse order of their development, which makes dIV the last one to disappear (Morse, 1872; Sewertzoff, 1931; Chiang et al., 2001; Shapiro et al., 2002).

From the molecular point of view, there are still standing questions over the exact roles of Shh signaling in the patterning of the AP axis and in determining digit number and identity (Tabin and McMahon, 2008; Harfe, 2011). Nevertheless, it is clear that, in the absence of Shh signaling from the mouse limb bud, the single digit that forms is the Shh-independent dl (Chiang et al., 2001; Ros et al., 2003), whereas progressive loss of Shh leads to dIV being lost last (Zhu et al., 2008). The detection of Shh in the hindlimb of Calyptommatus is an indication that the single-digit phenotype is different from the mouse mutant single-digit phenotype. In addition, Shh-null mice also show severe defects in the zeugopod (Chiang et al., 2001), which are not seen in Calyptommatus hindlimb. By combining molecular and morphological inferences, we could suggest that dIV is the remaining digit in the vestigial hindlimb of Calyptommatus (as previously interpreted in Roscito and Rodrigues, 2013), and that the absence of other digits may be explained by a failure in maintenance of Shh expression, as observed in Hemiergis lizards.

On the other hand, positional information may not always be a good proxy for determining digit identity and homology, given that patterning of digit identity can be uncoupled from the anatomical positioning of the cartilage condensation. The digits in the chicken wing and in both fore and hindlimb of the lizard Chalcides chalcides are examples where this uncoupling occurs: while anatomical analysis supports the identification of the digits as dI, dII, and dIII (in both the chicken and C. chalcides), gene expression analyses during limb development show that the digits are patterned as dII, dIII, and dIV (Wagner and Gauthier, 1999; Young et al., 2009). The Frame Shift Hypothesis (Wagner and Gauthier, 1999) accommodated these conflicting evidences by proposing a homeotic transformation of character identity.

The phalangeal number in the single digit of Calyptommatus hindlimb is reminiscent of $\mathrm{dl}$ from a pentadactyl condition, which might reflect a frame shift-like mechanism taking place in the patterning of this digit. Digit I develops in the anterior-most area of the hand/foot autopod where only Hoxd13, out of the distal Hoxd genes, is expressed (Montavon et al., 2008); thus, the absence of other distal Hoxd genes from the presumptive $\mathrm{dl}$ region is a reliable indication of $\mathrm{dl}$ fate - in fact, Hoxd11 and Hoxd12 expres- sion have been used to identify the homeotic frame shifts of the chicken and the lizard $C$. chalcides, as previously discussed. The investigation of the expression of the distal Hoxd genes in the hindlimb of Calyptommatus would be the conclusive evidence for determining if a homeotic shift would explain the digit configuration.

The extent to which disruptions in Shh signaling may be associated with changes in digit identity is still unknown. On one side, a change in downstream Shh signaling in bovine embryos results in a medial-distal shift of Hoxd13 expression, but the resulting digits do not have dl identity (Lopez-Rios et al., 2014). On the other hand, a shift in digit identity was observed in experimentally induced inhibitions of Shh in the chicken wing: digits I and II developed, but these digits formed in embryonic positions of dIII and dIV (Vargas and Wagner, 2009). Therefore, even though Shh was observed in Calyptommatus hindlimb, we cannot exclude the possibility of a downstream effect on its signaling cascade that could potentially induce a frame shift event.

The vestigial forelimb of Calyptommatus, represented by a small humerus located within the body wall, forms normally in early development but later degenerates (Roscito and Rodrigues, 2012b). Sonic hedgehog was not detected in this limb bud at any stage, showing that: i) Shh is not necessary for the emergence of the limb bud (consistent with previous results; Chiang et al., 2001; Ros et al., 2003); and ii) the absence of this patterning signal may be one of the factors involved in degeneration of the forelimb bud.

Remarkably, Shh is not expressed in the hindlimb buds of the dolphin, which degenerate during development, nor at those of python snake, which do not degenerate (Thewissen et al., 2006 and Cohn and Tickle, 1999, respectively). Because Shh is an important factor for maintenance of the AER signaling center, it would be expected that loss of Shh would affect the AER, and hence, limb bud development. The AER of the dolphin hindlimb is transient, which indicates that the limb bud degenerates because of the absence of AER-derived signaling. In contrast, the python snake hindlimb does not have a morphologically distinct AER nor expresses the genes normally associated with this signaling center (FGF, DIx, Msx; Cohn and Tickle, 1999), yet, it still develops to a vestigial structure. These contrasting scenarios show that further investigation is needed in order to determine the role of Shh in limb bud degeneration.

\section{Conclusions}

Considering the great diversity of limbs, it seems equally likely that there exists a corresponding diversity of mechanisms controlling the development of such structures. Minor limb reductions can be the result of diverse changes in the developmental program, such as differential regulation of specific signals or of its receptors. However, in greatly reduced limbs, the major signaling pathways (FGF and Shh signaling) seem to be consistently affected, which can represent a widespread case of convergence among tetrapods or nothing more than the relaxation of the selective pressures over such key signaling pathways after long evolutionary times. We are still distant from a comprehensive understanding of the anatomical diversity and evolutionary relationships among species, but we are much farther from understanding the mechanisms by which different limbs are formed, especially considering the dynamic properties of developmental systems. Increasing sam- 
pling of this diversity will dramatically widen our understanding of the robustness of the molecular developmental mechanisms and of the evolutionary forces that have been acting upon them.

\section{Materials and Methods}

\section{Material examined}

Our sample is comprised of 34 Gymnophthalmid genera and 70 species, out of a total of 46 genera and 244 species currently recognized for the group (reptile-database.org; august/2014). We included in our sampling only those species for which we could get information of the phalangeal formula, either by observing cleared and stained material, or by information from the literature.

Cleared and double stained specimens are from our personal collection and from the collection of Museu de Zoologia da Universidade de São Paulo; the material examined and respective collection numbers are listed in the supplementary information. The notation used for representing the phalangeal formula is the following:

(number of metacarpals/metatarsals) dl.dll.dll..dIV.dV; where $\mathrm{d}=$ digit

\section{Phylogenies of the Gymnophthalmidae}

Up to the present, there are three phylogenies for the Gymnophthalmidae (Pellegrino et al., 2001; Castoe et al., 2004; Pyron et al., 2013). The same species are consistently grouped together in all three phylogenies (Fig. 1). However, each author assigns each group to differently inclusive taxonomic rankings, which generates incongruences over the status of particular gymnophthalmid groups (see discussion in Rodrigues et al., 2007b, 2009). In this paper we do not wish to solve those incongruences, therefore our naming of the major groups and subgroups recognized within the Gymnophthalmid reflects our personal ideas regarding the evolution of these species:

Alopoglossinae (Pellegrino et al., 2001; Castoe et al., 2004): Alopoglossus, Ptychoglossus

Rachisaurinae (Pellegrino et al., 2001; Castoe et al., 2004): Rachisaurus

\section{Cercosaurinae}

Bachiini (Castoe et al., 2004): Bachia

Cercosaurini (Castoe et al., 2004): Cercosaura, Echinosaura, Neusticurus, Placosoma, Pholidobolus, Potamites, Proctoporus.

Ecpleopodinae (Castoe et al., 2004; Pyron et al., 2013): Anotosaura, Arthrosaura, Colobosauroides, Dryadosaura, Leposoma.

Gymnophthalminae

Heterodactylini (Rodrigues et al., 2009): Caparaonia, Colobodactylus, Heterodactylus

Iphisiini (Rodrigues et al., 2009): Acratosaura, Alexandresaurus, Colobosaura, Iphisa, Stenolepis

Gymnophthalmini (Pellegrino etal., 2001): Tretioscincus, Gymnophthalmus, Micrablepharus, Procellosaurinus, Psilophthalmus, Vanzosaura, Nothobachia, Scriptosaura, Calyptommatus

\section{Embryonic material and whole mount in-situ}

We obtained a small developmental series of five Calyptommatus sinebrachiatus embryos during a field trip to Bahia State, Brazil, in 2005, that were fixed in RNAlater after 6, 10, 12, 14, and 16 days after laying. The whole-mount in-situ hybridization for detection of the gene Sonic hedgehog followed a modified protocol used for chicken embryos, starting with two 5 -minute washes in $100 \%$ methanol, with a 1 -hour in between incubation in $6 \%$ hydrogen peroxide solution (in 100\% methanol). Following rehydration of the embryos in PBT, the embryos were subjected to a proteinase $\mathrm{K}$ digestion (20 minute reaction at room temperature) followed by re-fixation in 4\% PFA for 20 minutes. Embryos then went through to a series of 'preprobe' incubations in hybridization buffer and finally incubated overnight at $650 \mathrm{C}$ with a chicken-specific probe for Shh (1:10 dilution). After a series of washes with $\mathrm{MABT}$, and a blocking step, embryos were incubated overnight with anti-DIG (1:2000), and then the signal was revealed with NBT/BCIP.

\section{Acknowledgements}

Our work was supported by Conselho Nacional de Pesquisa (CNPq) and Fundação de Amparo à Pesquisa do Estado de São Paulo (FAPESP). JGR is truly grateful to Cheryll Tickle for helping in establishing the whole mount in situ. We are also greateful for the reviewer's constructive comments.

\section{References}

ALBERCH P, GALE EA. (1985). A developmental analysis of an evolutionary trend: digital reduction in amphibians. Evolution 39: 8-23.

BENESCH AR, WITHERS PC. (2002). Burrowing performance and the role of limb reduction in Lerista (Scincidae, Lacertilia). Senck leth 82: 107-114.

BERGMANN PJ, IRSCHICK DJ. (2009). Alternate pathways of body shape evolution translate into common patterns of locomotor evolution in two clades of lizards. Evolution 64: 1569-1582.

BOUGHNER JC, BUCHTOVÁ M, FU K, DIEWERT V, HALLGRÍMSSONB, RICHMAN JM. (2007). Embryonic development of Python sebae - I: Staging criteria and macroscopic skeletal morphogenesis of the head and limbs. Zoology 110:212-230.

BRANDLEY MC, HUELSENBECK JP, WIENS JJ. (2008). Rates and patterns in the evolution of snake-like body form in squamate reptiles: evidence for repeated re-evolution of lost digits and long-term persistence of intermediate body forms. Evolution 62: 2042-2064.

CALDWELL MW. (2002). From fins to limbs to fins: limb evolution in fossil marine reptiles. Am J Med Genet 112: 236-249.

CAMACHO A, PAVÃO R, MOREIRA CM, PINTO ACBCF, NAVAS CA, RODRIGUES MT. (2014). Interaction of morphology, thermal physiology and burrowing performance during the evolution of fossoriality in Gymnophthalmini lizards. Funct Ecol DOI: 10.1111/1365-2435.12355

CASTOE TA, DOAN TM, PARKINSON CL. (2004). Data partitions and complex models in Bayesian analysis: the phylogeny of gymnophthalmid lizards. Syst Biol 53: 448-469.

CHIANG C, LITINGTUNG Y, HARRIS MP, SIMANDL BK, LI Y, BEACHY PA, FALLON JF. (2001). Manifestation of the limb prepattern: limb development in the absence of sonic hedgehog function. Dev Biol 236: 421-435.

CHOQUENOT D, GREER AE. (1989). Intrapopulational and interspecific variation in digital limb bones and presacral vertebrae of the genus Hemiergis (Lacertilia, Scincidae). J Herp 23: 274-281.

COHN MJ, TICKLE C. (1999). Developmental basis of limblessness and axial patterning in snakes. Nature 399: 474-479.

COOPER KL, SEARS KE, UYGUR A, MAIER J, BACZKOWSKI K, BROSNAHAN M ANTCZAK D, SKIDMORE JA, TABIN CJ. (2014). Patterning and post-patterning modes of evolutionary digit loss in mammals. Nature 511: 41-45.

CRUMLY CR, SÁNCHEZ-VILLAGRA MR. (2004). Patterns of variation in the phalangeal formulae of land tortoises (Testudinidae): Developmental constraint, size, and phylogenetic history. J Exp Zool (Mol Dev Evol) 302B: 134-146.

CUNHA OR. (1970). Lacertílios da Amazônia, IV- Um novo gênero e espécie de lagarto do Território Federal do Amapá (Lacertilia-Teiidae). Bol Mus Para Emilio Goeldi Zool 74: 1-8.

DIXON JR. (1973). Asystematic review of the teiid lizards, genus Bachia, with remarks on Heterodactylus and Anotosaura. Univ Kansas Mus Nat Hist Misc Pub/57: 1-47.

DOROBA CK, SEARS KE. (2010). The divergent development of the apical ectodermal ridge in the marsupial Monodelphis domestica. Anat Rec 293: 1325-1332.

DUDLEYAT, ROS MA, TABIN CJ. (2002). Are-examination of proximodistal patterning during vertebrate limb development. Nature 418, 539-544.

FABREZI M, ABDALA V, MARTÍNEZ-OLIVER MI. (2007). Developmental basis of limb homology in lizards. Anat Rec (Hoboken) 290: 900-912.

GANS C. (1975). Tetrapod limblessness: evolution and functional corollaries. Am Zool 15: 455- 467

GREER AE. (1987). Limb reduction in the lizard genus Lerista. 1: Variation in the number of phalanges and presacral vertebrae. J Herpetol 21: 267-276.

GREER AE. (1991). Limb reduction in squamates: identification of the lineages and discussion of the trends. J Herpet 25: 166-173.

GRIZANTE MB. (2009). Relações evolutivas entre ecologia e morfologia serpentiforme em espécies de lagartos microteídeos (Sauria: Gymnophthalmidae). Unpublished 
thesis, Universidade de São Paulo. 103pp. Thesis published at teses.usp.br

HARFE BD. (2011). Keeping up with the zone of polarizing activity: new roles for an old signaling center. Dev Dyn 240: 915-919.

HOWES GB, SWINNERTON HH. (1901). On the development of the skeleton of the Tuatara, Sphenodon punctatus; with remarks on the egg, on the hatchling, and on the hatched young. Trans Zool Soc Lond 16: 1-86.

HUGI J, MITGUTSCH C, SÁNCHEZ-VILLAGRA MR. (2010). Chondrogenic and ossification patterns and sequences in White's skink Liopholis whitii (Scincidae, Reptilia). Zoosyst Evol 86: 21-32.

JEREZA, TARAZONAOA. (2009). Appendicular skeleton in Bachia bicolor(Squamata: Gymnophthalmidae): osteology, limb reduction and postnatal skeletal ontogeny. Acta Zool (Stockholm) 90: 42-50.

KEARNEY M, STUART BL. (2004). Repeated evolution of limblessness and digging heads in worm lizards revealed by DNA from old bones. Proc $R$ Soc Lond B 271: 1677-1683.

KIZIRIAN DA, MCDIARMID RW. (1998). A new species of Bachia (Squamata: Gymnophthalmidae) with plesiomorphic limb morphology. Herpetologica 54: 245-253.

KOHLSDORF T, WAGNER GP. (2006). Evidence for the reversibility of digit loss: a phylogenetic study of limb evolution in Bachia (Gymnophthalmidae: Squamata). Evolution 60: 1896-1912.

KOHLSDORF T, CUMMINGS MP, LYNCH VJ, STOPEPR GF, TAKAHASHI K, WAGNER GP. (2008). A molecular footprint of limb loss: sequence variation of the autopodial identity gene Hoxa-13. J Mol Evol 67: 581-593.

LANDE R. (1978). Evolutionary mechanisms of limb loss in tetrapods. Evolution 32: 73-92.

LAUFER E, NELSON CE, JOHNSON RL, MORGAN BA, TABIN C. (1994). Sonic hedgehog and Fgf-4 act through a signaling cascade and feedback loop to integrate growth and patterning of the developing limb bud. Cell 79: 993-1003.

LEAL L, TARAZONA OA, RAMÍREZ-PINILLA. (2010). Limb development in the gekkonid lizard Gonatodes albogularis: a reconsideration of homology in the lizard carpus and tarsus. J Morphol 27: 1328-1341.

LEWANDOSKI M, SUN X, MARTIN GR. (2000). Fgf8 signalling from the AER is essential for normal limb development. Nature Genet 26: 460-463.

LITINGTUNG Y, DAHN RD, LI Y, FALLON JF, CHIANG C. (2002). Shh and Gli3 are dispensable for limb skeleton formation but regulate digit number and identity. Nature 418: 979-983.

LOPEZ-RIOS J, DUCHESNE A, SPEZIALE D, ANDREY G, PETERSON KA GERMANN P, ÜNAL E, LIU J, FLORIOT S, BARBEY S et al. (2014). Attenuated sensing of SHH by Ptch1 underlies evolution of bovine limbs. Nature 511: 46-51.

MATHUR JK, GOEL SC. (1976). Patterns of chondrogenesis and calcification in the developing limb of the lizard, Calotes versicolor. J Morphol 149: 401-420.

MONTAVON T, GARREC JFL, KERZBERG M, DUBOULE D. (2008). Modelling HOX genes regulation in digits: reverse collinearity and the molecular origin of thumbness. Genes Dev 22: 236-259.

MORSE ES. (1872). On the tarsus and carpus of birds. Ann Lyc Nat HistNY10:141-158.

NISWANDER L, JEFFREY S, MARTIN GR, TICKLE C. (1994). A positive feedback loop coordinates growth and patterning in the vertebrate limb. Nature371:609-612.

NORO M, UEJIMAA, ABE G, MANABE M, TAMURAK. (2009). Normal developmental stages of the Madagascar ground gecko Paroedura pictus with special reference to limb morphogenesis. Dev Dyn 238: 100-109.

PELLEGRINO KCM, RODRIGUESMT, YONENAGA-YASSUDAY, SITES JW. (2001). A molecular perspective on the evolution of microteiid lizards (Squamata, Gymnophthalmidae), and a new classification for the family. Biol J Linn Soc 74: 315-38.

RAYNAUD A. (1963). La formation et la régression des ebauches des mernbres de l'embryon d'Overt (Anguis fragilis. L.). Observations effectuées sur les ébauches des membres postérieurs. Bull Soc Zool Fr 88: 299-324.

RAYNAUDA. (1990). Developmental mechanism involved in the embryonic reduction of limbs in reptiles. Int J Dev Biol 34: 233-243.

RAYNAUD A, KAN P, BOUCHE G, DUPRAT AM. (1998). Effects de divers facteurs de croissance (FGF, IGF-1) sur les ébauches des membres de l'embryon d'orvet (Anguis fragilis L.). Ann Sci Nat 3: 141-153.

RENOUS S, HÖFLING E, GASC JP. (1998). Respective role of the axial and appendicular systems in relation to the transition to limblessness. Acta Biotheor 46: 141-156.
RIEPPEL O. (1994). Studies on skeleton formation in reptiles. Patterns of ossification in the skeleton of Lacerta agilis exigua Eichwald (Reptilia, Squamata). J Herpetol. 28: 145-153.

RODRIGUESMT. (1997). Anew species of Leposoma(Squamata: Gymnophthalmidae) from the Atlantic forest of Brazil. Herpetologica 5: 383-389.

RODRIGUES MT, ÁVILA-PIRES TCS. (2005) New lizard of the genus Leposoma (Squamata, Gymnophthalmidae) from the lower Rio Negro, Amazonas, Brazil. $J$ Herpetol 39: 541-546.

RODRIGUES MT, DOS SANTOS EM. (2008). A new genus and species of eyelid-less and limb reduced gymnophthalmid lizard from northeastern Brazil (Squamata, Gymnophthalmidae). Zootaxa 1873: 50-60.

RODRIGUES MT, PAVAN DT, CURCIO FF. (2007). Two new species of lizards of the genus Bachia (Squamata, Gymnophthalmidae) from Central Brazil. J Herpetol 41: 545-553.

RODRIGUES MT, PELLEGRINO KCM, DIXO M, VERDADE VK, PAVAN D, ARGOLO AJS, SITES JW. (2007). A new genus of microteiid lizard from the atlantic forests of State of Bahia, Brazil, with a new generic name for Colobosaura mentalis, and a discussion of relationships among the Heterodactylini (Squamata, Gymnophthalmidae). Am Mus Novit 3565: 27pp.

RODRIGUESMT, CASSIMIROJ, PAVAND, CURCIOFF, VERDADE VK, PELLEGRINO KCM. (2009). A new genus of microteiid lizard from the Caparaó mountains, Southeastern Brazil, with a discussion of relationships among Gymnophthalminae (Squamata). Am Mus Novit 3673: 27pp.

RODRIGUES MT, TEIXEIRA JR M, RECODER RS, DAL VECHIO F, DAMASCENO R, PELLEGRINO KCM. (2013). A new species of Leposoma (Squamata: Gymnophthalmidae) with four fingers from the Atlantic Forest central corridor in Bahia, Brazil. Zootaxa 3635: 459-475.

ROMERAS. 1956. Osteology of the Reptiles. Chicago, IL: University of Chicago Press.

ROS MA, DAHN RD, FERNANDEZ-TERAN M, RASHKAK, CARUCCIO NC, HASSO SM, BITGOOD JJ, LANCMAN JJ, FALLON JF. (2003). The chick oligozeugodactyly (ozd) mutant lacks sonic hedgehog function in the limb. Development 130:527-537.

ROSCITO JG, RODRIGUES MT. (2012a). Skeletal development in the fossoria gymnophthalmids Calyptommatus sinebrachiatus and Nothobachia ablephara. Zoology 115: 289-301.

ROSCITO JG, RODRIGUES MT. (2012b). Embryonic development of the fossorial gymnophthalmid lizards Nothobachia ablephara and Calyptommatus sinebrachiatus. Zoology 115: 289-301.

ROSCITO JG, RODRIGUES MT. (2013). A comparative analysis of the post-cranial skeleton of fossorial and non-fossorial gymnophthalmid lizards. J Morphol 274 845-858.

RUSSELAP, BAUERAM. (2008). The appendicular locomotor apparatus of Sphenodon and normal-limbed squamates. In Biology of the Reptilia. Volume 21, Morphology I (Eds C Gans, AS Gaunt, K Adler). Society for the study of Amphibians and Reptiles, New Jersey: pp. 1-466.

SANZ-ESQUERRO JJ, TICKLE C. (2003). Digital development and morphogenesis. $J$ Anat 202: 51-58

SEWERTZOFF AN. (1931). Studien über die reduktion der organe der wirbeltiere. Zool Jahrb 53: 611-699.

SHAPIRO MD. (2002). Developmental morphology of limb reduction in Hemiergis (Squamata: Scincidae): chondrogenesis, osteogenesis, and heterochrony. J Morphol 254: 211-231

SHAPIRO MD, HANKEN J, ROSENTHAL N. (2003). Developmental basis of evolutionary digit loss in the Australian lizard Hemiergis. J Exp Zool B (Mol Dev Evol) 297B: 48-56.

SHAPIRO MD, SHUBIN NH, DOWNS JP. (2007). Limb diversity and digit reduction in reptilian evolution. In Fins into limbs: evolution, development, and transformation (Ed BK Hall). The University of Chicago Press, Chicago: pp. 225-244.

SHUBIN NH, ALBERCH P. (1986). A morphogenetic approach to the origin and basic organization of the tetrapod limb. Evol Biol 20: 319-387.

SKINNER A, LEE MSY, HITCHINSON MN. (2008). Rapid and repeated limb loss in a clade of scincid lizards. BMC Evol Biol 8: 310-318.

STRICKER S, MUNDLOS S. (2011). Mechanisms of digit formation: human malformation syndromes tell the story. Dev Dyn 240: 990-1004.

SUN X, MARIANI FV, MARTIN GR. (2002). Functions of FGF signalling from the apical ectodermal ridge in limb development. Nature 418: 501-508. 


\section{J.G. Roscito et al.}

TABIN CJ, MCMAHON AP. (2008). Grasping limb patterning. Science 321: 350-352.

TE WELSCHER P, FERNANDEZ-TERAN M, ROS MA, ZELLER R. (2002). Mutual genetic antagonism involving GLI3 and dHAND prepatterns the vertebrate limb bud mesenchyme prior to SHH signaling. Genes Dev. 16: 421-426.

THEWISSEN JGM, COHN MJ, STEVENS LS, BAJPAI S, HEYNING J, HORTON JR. WE. (2006). Developmental basis for hindlimb loss in dolphins and origin of the cetacean bodyplan. Proc. Natl. Acad. Sci. USA 103: 8414-8418.

THOMAS RA. (1965). A new species of Bachia (Sauria: Teiidae) from Brasil. Herpetologica 21: 18-22.

UETZ P, JIRÍ HOSEK (eds). The Reptile Database, http://www.reptile-database.org, accessed Oct, 2014.

WANG B, FALLON JF, BEACHY PA. (2000). Hedgehog-regulated processing of Gli3 produces an anterior/posterior repressor gradient in the developing vertebrate limb. Cell 100: 423-434.

WHITING AS, BAUER AM, SITES JW. (2003). Phylogenetic relationships and limb loss in sub-Saharan African scincine lizards (Squamata: Scincidae). Mol Phylogenet Evol 29: 582-598.

WIENS JJ, Brandley MC, Reeder TW. (2006). Why does a trait evolve multiple times within a clade? Repeated evolution of snake-like body form in squamate reptiles. Evolution 60: 123-141.
PYRON RA, BURBRINK FT, WIENS JJ. (2013). A phylogeny and revised classification of Squamata, including 4161 species of lizards and snakes. BMC Evol Biol 13: 93-140.

VARGAS AO, WAGNER GP. (2009). Frame-shifts of digit identity in bird evolution and cyclopamine-treated wings. Evol Dev 11: 163-169.

WAGNER GP, GAUTHIER JA. (1999). 1,2,3 = 2,3,4: a solution to the problem of the homology of the digits in the avian hand. Proc Natl. Acad Sci USA 96: 5111-5116.

WITHERS PC. (1981). Physiological correlates of limblessness and fossoriality in scincid lizards. Copeia 1981: 197-204.

YOUNG RL, CAPUTO V, GIOVANNOTTI M, KOHLSDORF T, VARGAS AO, MAY GE, WAGNER GP. (2009). Evolution of digit identity in the three-toed Italian skink Chalcides chalcides: a new case of digit identity frame shift. Evol Dev11:647-658.

YOUNG RL, BEVER GS, WANG Z, WAGNER GP. (2011). Identity of the avian wing digits: problems resolved and unsolved. Dev Dyn 240: 1042-1053.

ZHU J, NAKAMURA E, NGUYEN M, BAO X, AKIYAMA H, MACKEM S. (2008). Uncoupling Sonic hedgehog control of pattern and expansion of the developing limb bud. Dev Cell 14: 624-632.

ZUNIGA A, HARAMIS AP, MCMAHON AP, ZELLER R. (1999). Signal relay by BMP antagonism controls the SHH/ FGF4 feedback loop in vertebrate limb buds. Nature 401: 598-602. 


\section{Further Related Reading, published previously in the Int. J. Dev. Biol.}

Developmental basis of limb evolution

J Richard Hinchliffe

Int. J. Dev. Biol. (2002) 46: 835-845

Developmental mechanism involved in the embryonic reduction of limbs in reptiles A Raynaud

Int. J. Dev. Biol. (1990) 34: 233-243

Limb pattern, physical mechanisms and morphological evolution - an interview with Stuart A. Newman

Cheng-Ming Chuong

Int. J. Dev. Biol. (2009) 53: 663-671

Generation of pattern and form in the developing limb

Matthew Towers and Cheryll Tickle

Int. J. Dev. Biol. (2009) 53: 805-812

Interplay between the molecular signals that control vertebrate limb development Lee Niswander

Int. J. Dev. Biol. (2002) 46: 877-881

5 yr ISI Impact Factor $(2013)=2.879$
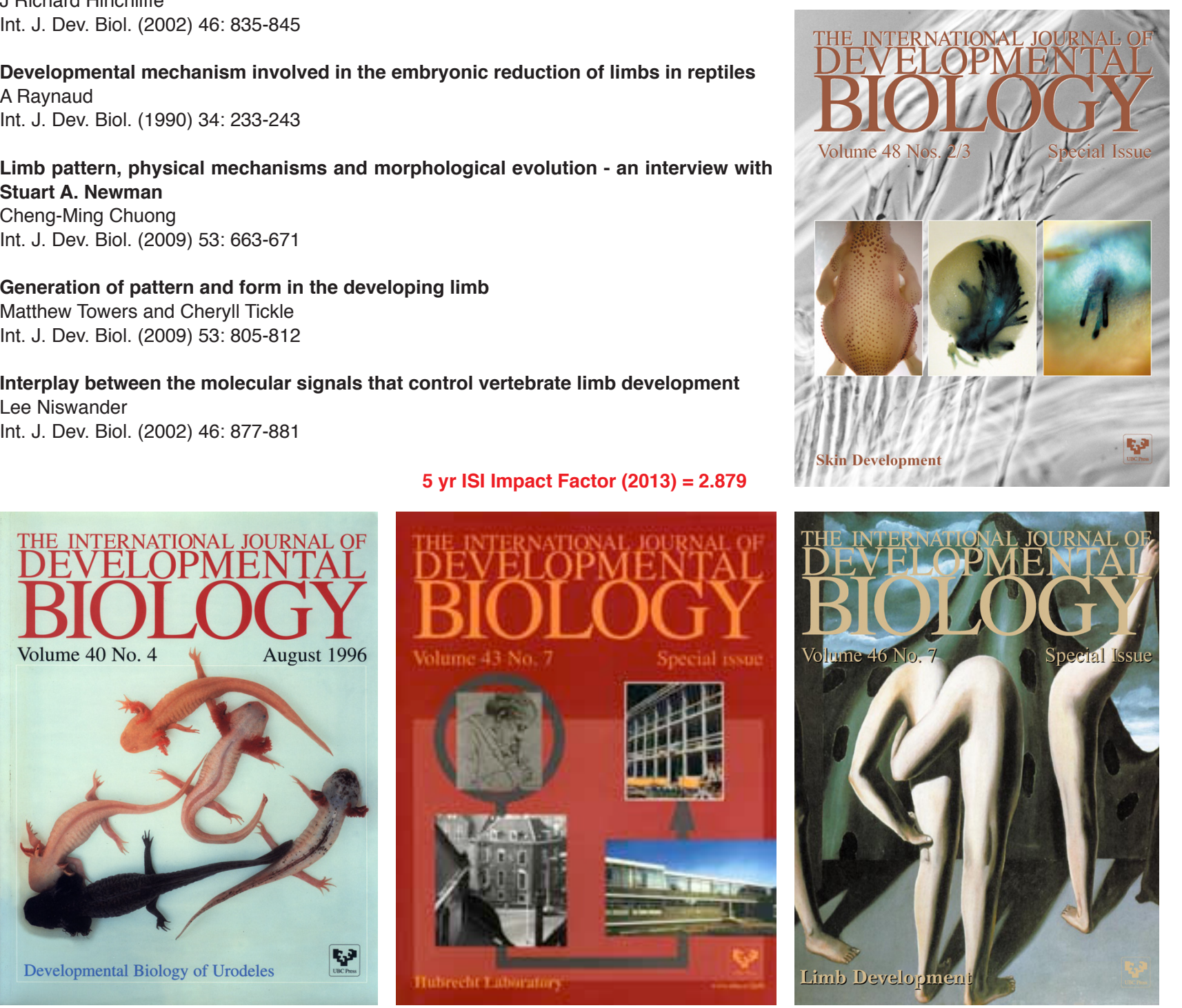